PontIFícIA UNIVERSIDADE CATÓLICA dO RIO DE JANEIRO

\title{
O Comportamento de Compra do Consumidor no Mercado Livre.
}

\section{Bernardo Caulliraux Camarotti}

Trabalho de Conclusão de Curso

Centro de CIÊnCIAS SOCIAIS - CCS

DEPARTAMENTO DE ADMINISTRAÇÃO

Graduação em Administração de Empresas 
Bernardo Caulliraux Camarotti

\section{O Comportamento de Compra do Consumidor no Mercado}

Livre.

Trabalho de Conclusão de Curso

Trabalho de Conclusão de Curso, apresentado ao programa de graduação em Administração da PUC-Rio como requisito parcial para a obtenção do título de graduação em Administração.

Orientador(a): Daniel Kamlot

Rio de Janeiro, novembro de 2021. 


\title{
Resumo
}

CAMAROTTI, Bernardo. O Comportamento de Compra do Consumidor no Mercado Livre. Rio de Janeiro, 2021. 53p. Trabalho de Conclusão de Curso - Departamento de Administração. Pontifícia Universidade Católica do Rio de Janeiro.

\begin{abstract}
O presente estudo teve como objetivo analisar todo o comportamento dos consumidores do e-marketplace Mercado Livre durante o processo de decisão de compra de um produto anunciado no site. A plataforma possui diversos anúncios ofertando o mesmo produto, assim buscando identificar os principais pontos que levam o consumidor a escolher em qual irá realizar a compra. A partir desta perspectiva, a análise baseou-se em identificar os pontos fortes e fracos dos anúncios e anunciantes e definir as principais ações que devem ser tomadas pelos mesmos para alcançar uma maior quantidade de vendas. Foi realizada uma pesquisa quantitativa com caráter exploratório e descritivo no Google Forms, com 142 pessoas. A pesquisa apurou dados demográficos e do comportamento de compra do consumidor dentro da plataforma Mercado Livre.
\end{abstract}

Palavras- chave

Comportamento do Consumidor. Mercado Livre. e-marketplace. Decisão de Compra. E-commerce. 


\section{Abstract}

CAMAROTTI, Bernardo. Consumer Buying Behavior in the Mercado Livre. Rio de Janeiro, 2021. 53p. Trabalho de Conclusão de Curso Departamento de Administração. Pontifícia Universidade Católica do Rio de Janeiro.

This study aimed to analyze the entire behavior of e-marketplace Mercado Livre consumers during the decision process to purchase a product advertised on the website. The platform has several ads offering the same product, thus seeking to identify the main points that lead the consumer to choose which one to make the purchase. From this perspective, the analysis was based on identifying the strengths and weaknesses of the ads and advertisers and defining the main actions that should be taken by them to achieve a greater amount of sales. Quantitative research with an exploratory and descriptive character was carried out on Google Forms, with 142 people. The survey found demographic data and consumer buying behavior within the Mercado Livre platform.

Key-words

Consumer behavior. Mercado Livre. e-marketplace. Buying decision. Ecommerce. 


\section{Agradecimentos}

Agradeço aos meus pais Marcelo e Maria Lúcia por todo o suporte e por acreditarem em mim em todos os momentos. Sem vocês, não seria possível a realização de mais uma etapa super importante na minha vida.

Aos meus amigos que estão do meu lado há anos e me deram suporte nos momentos mais difíceis em todo o período, obrigado por tanto.

Aos amigos feitos durante a graduação, vocês foram primordiais nessa nova conquista. Agradeço por todos os dias juntos na PUC-Rio e pelos momentos alegres que partilhamos juntos.

Agradeço ao meu orientador e professor Daniel Kamlot, por todas as ajudas e reuniões para que a pesquisa fosse desenvolvida da melhor maneira possível. 


\section{Sumário}

1. O tema e o problema de estudo 1

1.1 Introdução ao tema e ao problema do estudo 1

1.2 Objetivo do estudo 2

1.3 Objetivos específicos do estudo 2

$\begin{array}{lll}1.4 & \text { Delimitação do estudo } & 3\end{array}$

1.5 Justificativa e relevância do estudo 3

2. Referencial Teórico 5

2.1 Comportamento do Consumidor 5

2.1.1 O processo de decisão de compra do consumidor $\quad 7$

2.2 E-commerce 9

$\begin{array}{lll}2.3 & \text { E-Marketplace } & 10\end{array}$

$\begin{array}{ll}\text { 2.3.1. Mercado Livre } & 13\end{array}$

3. Métodos e procedimentos de coleta e de análise de dados do estudo 15

$\begin{array}{lll}3.1 & \text { Tipo de Pesquisa } & 15\end{array}$

$\begin{array}{lll}3.2 & \text { População e amostra } & 15\end{array}$

$\begin{array}{lll}3.3 & \text { Coleta de dados } & 16\end{array}$

$\begin{array}{lll}3.4 & \text { Limitações do Método } & 16\end{array}$

4. Apresentação e análise dos resultados 18

$\begin{array}{lll}4.1 & \text { Perfil dos respondentes } & 18\end{array}$

$\begin{array}{lll}4.1 .1 & \text { Sexo } & 18\end{array}$

$\begin{array}{lll}4.1 .2 & \text { Idade } & 19\end{array}$

4.1.3 Região em que residem 20

$\begin{array}{lll}\text { 4.1.4 Consumidores de e-commerce } & 21\end{array}$

4.1.5 Consumidores de e-commerce na pandemia 22

4.1.6 Consumidores do e-marketplace 23

$\begin{array}{lll}4.2 & \text { Análise dos resultados } & 23\end{array}$

4.2.1 Como conheceu o Mercado Livre 23

4.2.2 O que faz escolher o Mercado Livre para a compra de um produto 25

4.2.3 Avaliação dos anunciantes da plataforma 26

4.2.3.1 Preço 26

$\begin{array}{lll}\text { 4.2.3.2 } & \text { Marca } & 28\end{array}$ 
4.2.3.3 Reputação do vendedor 29

4.2.3.4 Quantidade de vendas que o anúncio possui 30

$\begin{array}{lll}\text { 4.2.3.5 Frete Grátis } & 31\end{array}$

4.2.3.6 Entrega do produto no dia seguinte após a compra 32

4.2.3.7 Empresa vendedora conhecida (ex: Loja da Americanas.com dentro do Mercado Livre) 33

4.2.4 Motivos da desistência de uma compra no Mercado Livre 34

4.2.5 Avaliação do processo de compra na plataforma 36

4.2.6 Recomendação do Mercado Livre para outras pessoas 37

5. Conclusões e recomendações para novos estudos 38

6. Referências Bibliográficas $\quad 40$ 


\section{O tema e o problema de estudo}

\subsection{Introdução ao tema e ao problema do estudo}

Entender o que leva o consumidor a comprar um produto em determinada loja ou de determinado anunciante é essencial para o negócio, sendo um dos requisitos principais para o sucesso de uma loja. Muito além de ter um processo bem estruturado de vendas, é necessário compreender como o cliente pensa e age, assim sendo possível planejar e atender essa demanda. Mas o que seria esse comportamento de compra do consumidor?

Trata-se de um estudo de como pessoas selecionam, compram, usam e descartam tanto produtos quanto serviços para satisfazerem suas necessidades e seus desejos. Isso representa o processo e decisão de compra que os consumidores passam antes de comprar alguma coisa. Muitas empresas pensam que conhecem o comportamento de compra de seus consumidores, mas cada vez mais os clientes estão sendo mais criteriosos antes de realizar uma compra e mudando de ideia por motivos simples ou até mesmo não conhecendo os próprios motivos que o levam à decisão. (MARCUS MIKAI, 2020).

Pesquisas da UPS Pulse of The Online Shopper (2019) mostraram que cerca de $96 \%$ dos compradores globais online (95\% no Brasil) utilizam os emarketplaces (GLOBO, 2019) e cerca de $36 \%$ dos consumidores em todo o mundo (e $44,1 \%$ dos brasileiros) pretendem aumentar as compras de produtos por esse canal nos próximos 12 meses. Em todo o mundo, $48 \%$ dos consumidores fazem compras por impulso nessas plataformas. (ECOMMERCE BRASIL, 2019).

O comportamento de compra de consumidores dentro dos e-marketplaces se dá pela grande facilidade de ver diversas ofertas do mesmo produto em anúncios de vendedores diferentes, podendo comparar preços, condições de entrega, reputações dos anunciantes e os mais requisitados pelos consumidores. Essa facilidade ocorre pelo site conseguir mostrar toda essa 
variedade em uma única página, possibilitando ao cliente escolher o melhor produto e serviço para poder realizar a compra.

Cada vez mais esses e-marketplaces estão se aprofundando, entendendo e dando a devida importância para as decisões que levam um consumidor a comprar determinado produto, oferecendo entregas no mesmo dia e ranqueando cada vez melhor os anúncios com boas reputações.

Com a pandemia do COVID-19, é perceptível que diversos negócios estão se digitalizando em uma busca de novas alternativas de venda, e uma dessas formas de aumentar a quantidade de vendas é a busca por anúncios em emarketplaces, visto que apenas precisam pagar uma pequena taxa após a venda do produto, não sendo necessário um investimento inicial na plataforma. Esse modelo de negócio popular é promissor e já reúne a maior quantidade de vendas da internet. (RIBEIRO, 2020)

Marketplaces são plataformas que reúnem várias lojas de diversos segmentos. São conhecidos como sites com grandes volumes de tráfego diariamente. As lojas mais conhecidas no Brasil hoje praticam essa funcionalidade, dentre elas estão o Mercado Livre, Lojas Americanas e OLX (ECCOMERCE BRASIL, 2017).

Considerando esses fatos, este estudo vai responder ao seguinte problema: Que fatores levam o consumidor final a comprar um produto de certo vendedor dentro do e-marketplace Mercado Livre em detrimento das demais inúmeras ofertas idênticas?

\subsection{Objetivo do estudo}

O objetivo principal do estudo é analisar os principais fatores que levam o consumidor final a comprar um produto de um determinado vendedor dentro do e-marketplace Mercado Livre, considerando que, na plataforma, existem milhares de ofertas idênticas do mesmo item.

\subsection{Objetivos específicos do estudo}

Para atingir o objetivo proposto neste estudo, os seguintes objetivos específicos serão atendidos:

$\boldsymbol{V}$ Investigar se a pandemia incentivou os consumidores a adquirirem mais produtos através da internet. 
$\checkmark \quad$ Investigar quais as razões para a escolha da plataforma do Mercado Livre.

$\boldsymbol{V} \quad$ Investigar as razões para a escolha de um determinado anúncio no meio de milhares idênticos.

$\boldsymbol{V}$ Investigar os atributos do anúncio que agradam e incomodam o comprador no momento de análise dos anúncios.

$\checkmark \quad$ Identificar o processo de decisão de compra dos consumidores de marketplaces.

$\checkmark \quad$ Investigar como a persuasão de frete grátis e entregas no mesmo dia motivam a decisão de compra do consumidor no emarketplace em questão.

\subsection{Delimitação do estudo}

O estudo se limitou a analisar os dados coletados através da participação de pessoas do sexo masculino e feminino, com faixa etária a partir de 17 anos. O foco da pesquisa foi na integração e operação com consumidores presentes somente no Brasil.

O objetivo do estudo visa identificar a influência de cada detalhe do emarketplace, desde a escolha do Mercado Livre até o que motiva a compra de um produto ou serviço dentro da plataforma, dado que existem diversos anúncios na mesma página de diversos vendedores diferentes.

O foco deste estudo recai somente no e-marketplace Mercado Livre. Tal escolha vem do grande sucesso do site e pela grande facilidade e acesso a informações cruciais do estudo.

A busca por informações dos compradores abrange tanto o gênero masculino quanto o feminino, visto que o Mercado Livre atende a demanda dos dois potenciais gêneros de clientes.

\subsection{Justificativa e relevância do estudo}

O estudo é relevante para empresas e vendedores que atuam em marketplaces, visto que discute os principais fatores que levam os consumidores a escolherem um anúncio para a compra levando em consideração a existência de milhares de anúncios idênticos do mesmo produto, tendo como objetivo compreender o que leva o consumidor final a acessar o site e realizar uma 
compra no e-marketplace mais acessado do Brasil, sendo um modelo de negócio em destaque no Brasil e no mundo. 


\title{
2. Referencial Teórico
}

\subsection{Comportamento do Consumidor}

O comportamento de compra do consumidor é um estudo baseado no processo de escolha do indivíduo ou de grupo de pessoas, as quais selecionam, compram, usam ou descartam produtos ou serviços para contentar seus desejos (SOLOMON, 2016).

Segundo Solomon (2016, p.6), comportamento do consumidor significa:

\begin{abstract}
O campo de comportamento do consumidor abrange uma extensa área: é o estudo dos processos envolvidos quando indivíduos ou grupos selecionam, compram, usam ou descartam produtos, serviços, ideias ou experiências para satisfazerem necessidades e desejos. Os consumidores assumem várias formas, desde uma criança de oito anos que pede à mãe um bicho de pelúcia Webkinz a um executivo de uma grande corporação que escolhe um sistema de computador de vários milhões de dólares. Os itens consumidos podem ser desde ervilhas em lata a uma massagem, democracia, jeans Juicy, música reggaeton ou uma celebridade como Adele. As necessidades e os desejos a serem satisfeitos variam de fome e sede a amor, status ou realização espiritual.
\end{abstract}

Para Kotler e Keller (2012, p.164) o comportamento do consumidor estuda como pessoas, grupos e organizações selecionam, compram, usam e descartam bens, artigos, serviços, ideias e até mesmo experiências para buscar satisfazer suas necessidades e desejos. Os profissionais que trabalham na área de marketing e vendas devem dominar o comportamento de compra do consumidor, tanto na teoria como na prática.

Segundo Solomon (2016), entender o comportamento do consumidor é um dos principais fatores para as empresas atingirem suas metas, visto que as ações de marketing devem ser direcionadas o melhor possível para o seu público-alvo, tentando, assim, obter os melhores resultados possíveis. Identificar 
quem são, onde estão localizados, como se comportam, gênero, estrutura familiar, classe social e renda, raça e etnicidade, idade e estilo de vida é de extrema importância para o êxito de qualquer empresa que vende produto ou serviço.

Kotler e Keller (2012) afirmam que o comportamento de compra do consumidor é influenciado por determinados fatores, sendo eles os culturais, sociais e pessoais.

Os fatores culturais são os que mais exercem influência, sendo determinantes nos desejos e no comportamento de uma pessoa. $O$ fator cultural envolve a cultura, subcultura e a classe social do indivíduo. A cultura é baseada nos valores, preferências e comportamento das pessoas. A subcultura está mais relacionada a nacionalidades, religiões, grupos raciais, idade e regiões geográficas. São identificações mais específicas. Por último, a classe social é baseada no poder aquisitivo das pessoas, sendo o indivíduo tendo determinado estilo de vida baseado na sua riqueza (KOTLER e KELLER, 2012, p. 165).

Os fatores sociais englobam os grupos de referência, sendo eles os que mais exercem determinada influência, seja diretamente ou indiretamente no comportamento do indivíduo. Os grupos de afinidade exercem influência direta no comportamento. Sendo eles a família, amigos, vizinhos e colegas de trabalho, tendo em vista a interação contínua, informal e diária. Os grupos secundários, formados por grupos religiosos ou associações de classe, costumam ter interações mais formais e menos diretas, influenciando menos (KOTLER e KELLER, 2012, p. 165).

Por último, os fatores pessoais envolvem as características pessoais, como idade e estágio no ciclo de vida, circunstâncias econômicas, personalidade e autoimagem, estilo de vida e valores. Essas características tendem a ter um impacto direto no comportamento do consumidor. Com o avanço da idade e estágio no ciclo de vida, os desejos e as necessidades vão se moldando e alterando, tendo um impacto no comportamento e preferência do consumidor. A ocupação e circunstâncias econômicas dos indivíduos também influenciam no seu padrão de consumo, tendo em vista que pessoas com poderes aquisitivos maiores, tendem a ter maiores exigências de consumo, acompanhado do seu estilo de vida e valores (KOTLER e KELLER, 2012, p. 167).

Entender o consciente do consumidor é essencial para compreender 0 comportamento do comprador. A busca se trata do entendimento da chegada do estímulo externo até a decisão de compra. Esses fatores psicológicos são 
formados pela motivação, percepção, aprendizagem e memória. A figura 1 contém o modelo do comportamento do consumidor (KOTLER e KELLER, 2012).

Figura 1: Modelo do Comportamento do Consumidor

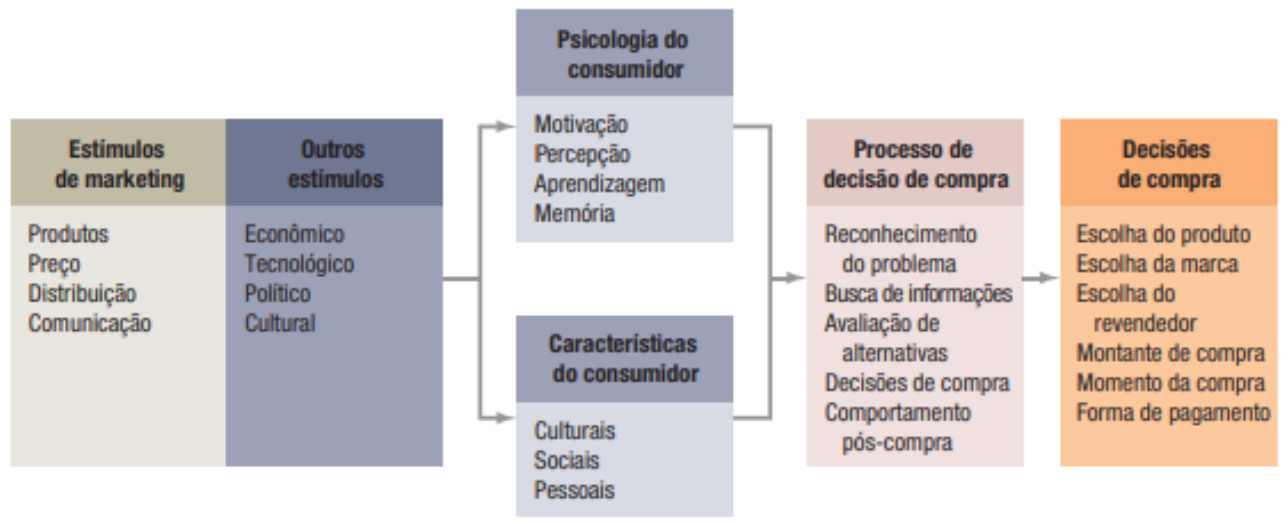

Fonte: Kotler, Keller (2012, p. 172)

\subsubsection{O processo de decisão de compra do consumidor}

Segundo Kotler e Keller (2012) o processo de decisão de compra do consumidor é um modelo dividido em estágios. As cinco etapas que formam o processo decisório de compra dos consumidores estão na figura 2. 
Figura 2: Modelo das cinco etapas do processo de compra do consumidor.

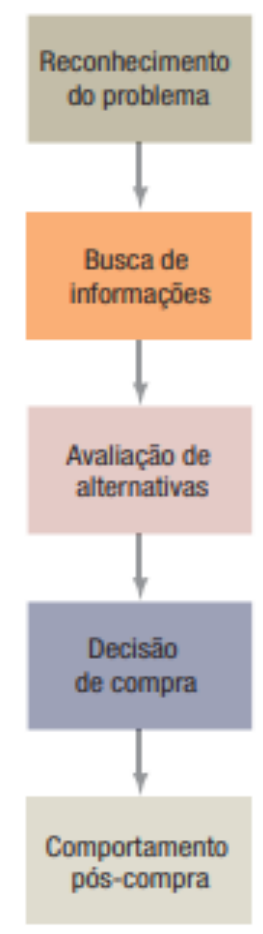

Fonte: Kotler, Keller (2012, p. 179)

A primeira etapa ocorre quando o comprador percebe uma necessidade ou problema desencadeado de uma diferença significativa do seu estado de estímulo atual e outro estado que se deseja alcançar (SOLOMON, 2016).

Após o reconhecimento da necessidade ou problema, o consumidor passa para a segunda etapa, na qual busca dados para tomar uma decisão. Os consumidores vão atrás de informações, sendo elas, de acordo com Solomon (2016), de:

- Pessoas, amigos e família;

- Comerciais;

- Experimentais, que é através do uso e experimento do produto.

Após buscar o máximo de informações disponíveis, o consumidor chega à terceira etapa, em que avalia as alternativas encontradas, comparando as opções potenciais, podendo avaliar diversos fatores. Peter e Olson (2009) afirmam que as consequências que o consumidor utiliza para decidir entre as alternativas são conhecidas como critérios de escolha. A escolha do item leva em consideração consequências funcionais, como o desempenho do produto, a 
admiração dos amigos, ou até mesmo as de valor como a sensação de realização ou autoestima. Todo consumidor possui crenças que interferem ou levantam a consideração em adquirir determinado produto.

Levando em consideração os e-marketplaces, o consumidor que faz uma busca no Mercado Livre por um determinado produto deve escolher entre as diversas lojas existentes no site, analisando em qual das opções a compra trará uma maior sensação de realização ou até mesmo de autoestima.

Após a avaliação das alternativas, a quarta etapa baseia-se na decisão de compra, na qual o consumidor escolhe o produto que mais lhe satisfaz. Kotler e Keller (2012) afirmam que após o estágio de avaliação, os consumidores podem decidir qual produto comprar, considerando cinco fatores: marca, revendedor, quantidade, ocasião e formas de pagamento.

A última etapa é o comportamento pós-compra, em que o comprador avalia como a empresa o trata após adquirir o produto ou serviço prestado. Uma empresa nunca deve finalizar o contato com o cliente após o produto ter sido comprado. A organização deve estar sempre atenta e monitorar a satisfação do cliente perante o produto adquirido, buscando receber a maior quantidade possível de feedback. A satisfação do cliente está relacionada com a sua expectativa sobre o produto/serviço e o desempenho percebido. Se por algum motivo, gerar desapontamento, o cliente ficará insatisfeito. Caso contrário, a superação de expectativas gera um encantamento e retorno do cliente à loja. Todos os sentimentos influenciam na volta ou não do cliente à loja e se recomendam ou não para outras pessoas. (KOTLER e KELLER, 2012).

\subsection{E-commerce}

De acordo com Salvador e Miranda (2013), comércio eletrônico, mais conhecido como e-commerce, é todo tipo de transação feita através de meios eletrônicos. A internet popularizou esse tipo de transação pelo mundo, principalmente após aumentar a garantia da segurança de dados, assim as pessoas se sentem mais confortáveis e corajosas para digitarem seus dados pessoais nos sites.

Já Bertholdo (2021) atrela e-commerce à comercialização de serviços e produtos por meio de plataformas e dispositivos eletrônicos usando a internet. $O$ surgimento do comércio eletrônico veio após a percepção de que a única 
maneira de comprar algo era por intermédio de lojas físicas. Isso possibilitou que as pessoas pudessem comprar produtos de qualquer lugar do mundo.

Bertholdo (2021) cita que o tipo de e-commerce mais conhecido e consumido na atualidade é a loja virtual. Porém, o marketplace também é bastante famoso e utilizado. Será aprofundado sobre o famoso "shopping virtual" no tópico 2.3.

Ainda para Salvador e Miranda (2013), o comércio eletrônico possui diversas variações, sendo elas o B2C - business-to-consumer (venda de empresas diretamente para o consumidor final); B2B - business-to-business (empresas vendem para outras empresas); C2C - consumer-to-consumer (comércio entre dois consumidores, por exemplo, a venda de um produto usado para uma outra pessoa); B2G - business-to-goverment (venda de produtos/serviços de empresas para o governo).

\subsection{E-Marketplace}

O mercado de vendas pela internet no Brasil e no mundo passa por um processo de desconcentração. O mercado de e-commerce é liderado por grandes empresas varejistas e marcas próprias que migraram ou possuem parte de seu negócio no mundo digital. Com essa mudança, é cada vez mais perceptível um novo movimento do varejo eletrônico, consolidado por novos modelos de negócios e agregadores de lojas. (MASCARENHAS, 2018).

Ainda para Mascarenhas (2018), o e-marketplace é um desses modelos de negócio agregadores, tendo em vista que uma plataforma online une as diversas ofertas de inúmeras lojas virtuais ali presentes, facilitando o consumidor e agregando a experiência de compra, pagamento e até mesmo a entrega.

De acordo com CHO (2016 apud Silva, Senra, Jacomino, Guarnieri e Britto, 2018) marketplaces são mercados que unem diversos vendedores, seja no âmbito físico ou on-line. Tendo em vista o grande e rápido crescimento do uso da tecnologia nos negócios, principalmente a Internet, um fenômeno que vem se desenvolvendo ao longo dos anos conhecido como marketplace online, chamados de e-marketplace.

E de acordo com o SEBRAE (2021), e-marketplace nada mais é que uma loja virtual que reúne diversos vendedores. As plataformas são conhecidas por conectar diretamente os fornecedores aos seus clientes. Nesse modelo de negócio, tanto os compradores quanto os vendedores têm possibilidades de obter valores mais acessíveis e uma melhor margem de lucro. Os vendedores 
pagam uma taxa para o site apenas quando vendem o produto ou serviço. Esse modelo de negócio gera uma grande oportunidade para pequenos negócios, tendo em vista que as taxas só serão pagas após a venda.

Segundo Wertz e Kingyens (2015), e-marketplace é um tipo de ecommerce que busca conectar os vendedores com os compradores. Os compradores e vendedores optam pela plataforma por terem problemas de se encontrar em pesquisas, portanto, os sites que praticam e-marketplace criam uma eficiência para o mercado.

O e-marketplace tem por sua característica promover somente produtos e serviços de terceiros, atuando na mediação entre os lojistas e consumidores, ainda assim cuidando de todo o processo, desde a compra até o recebimento da mercadoria. Também possui a possibilidade de ser C2C, ou Consumer-ToConsumer, possibilitando a vendas de pessoas físicas pela plataforma digital, não sendo limitado apenas a empresas. Um exemplo de modelo de negócio é o Mercado Livre, que abordaremos no tópico 2.3.1. Existem os marketplaces híbridos, em que a própria empresa anuncia seus produtos, mas também conta com lojas de terceiros. É o caso da plataforma da Amazon. (MASCARENHAS, 2018).

Segundo Wertz e Kingyens (2015), existem 3 tipos de marketplaces, sendo eles categorizados em:

- $\quad$ P2P (peer-to-peer): Os marketplaces oferecem aos usuários uma plataforma para compartilhamento de produtos ou serviços. As transações são feitas por pessoas privadas. Um exemplo foram os primeiros dias do eBay e Airbnb.

B2B (business-to-business): Esse modelo acabou perdendo forças e ficando atrás do modelo P2P e B2C. É um modelo de marketplace totalmente voltado para empresas. A plataforma é um intermédio na ligação dos negócios.

- $\quad$ B2C (business-to-consumer): É o mais comum. Esse modelo envolve a transação da empresa diretamente com o cliente final.

Ribeiro (2021) apurou as principais comissões que devem ser pagas nos e-marketplaces. As taxas das plataformas são cobradas apenas quando o produto é vendido dentro dos sites e o percentual cobrado é determinado sobre o valor total do produto. Os valores podem variar de acordo com o plano que o 
vendedor seleciona e até mesmo com o quão exposto seus produtos ficarão dentro da plataforma.

A plataforma do Mercado Livre (2021) cita os valores cobrados por cada produto vendido dentro do site. A tabela 1, a seguir, apresenta os valores das tarifas cobradas pela plataforma.

Tabela 1: Tarifa de venda no Mercado Livre

\begin{tabular}{|c|c|c|}
\hline \multirow{2}{*}{ Cotegorios } & Clássico & Premium \\
\hline & \multicolumn{2}{|c|}{ +f\$ 5 por uridede am produteu abeivo do f\$ 79} \\
\hline Celulares e Smertphones & $11 \%$ & $16 \%$ \\
\hline Suplementos & $12 \%$ & $17 \%$ \\
\hline Ténis & $14 \%$ & $19 \%$ \\
\hline Luminéries de Teto, Solares e Arandelas & $11.5 \%$ & $16.5 \%$ \\
\hline Notebooks & $11 \%$ & $16 \%$ \\
\hline Tratementos pere o Cabelo & $11 \%$ & $16 \%$ \\
\hline Calques & $14 \%$ & $19 \%$ \\
\hline Fones e Heodsets & $13 \%$ & $18 \%$ \\
\hline Camisoles e moletons & $14 \%$ & $19 \%$ \\
\hline Botas & $14 \%$ & $19 \%$ \\
\hline Bicicletes & $11.5 \%$ & $16.5 \%$ \\
\hline$H D=$ e SSDe & $13 \%$ & $18 \%$ \\
\hline Roteodores & $13 \%$ & $18 \%$ \\
\hline Relógios de Pulso & $14 \%$ & $19 \%$ \\
\hline Smertwetches & $11 \%$ & $16 \%$ \\
\hline Computedores & $11 \%$ & $16 \%$ \\
\hline Impressoras & $11 \%$ & $16 \%$ \\
\hline Televisores & $11 \%$ & $16 \%$ \\
\hline Coixas de Som e Autofalantes & $13 \%$ & $18 \%$ \\
\hline Media Streaming & $11 \%$ & $16 \%$ \\
\hline Para conferir outres te & buecand & \\
\hline
\end{tabular}

Fonte: Mercado Livre (2021)

O próprio site do Mercado Livre (2021) assume que os anúncios feitos no site são gratuitos, e as taxas são cobradas apenas quando a venda é realizada. 


\subsubsection{Mercado Livre}

Fundado em 1999, o Mercado Livre é a companhia líder na oferta de tecnologia para o comércio eletrônico na América Latina e oferece soluções para que indivíduos e empresas possam comprar, vender, anunciar, enviar e pagar bens e serviços na Internet. A empresa atende a milhões de usuários, criando um ecossistema online para a negociação de uma ampla variedade de bens e serviços de forma fácil, segura e eficiente. $O$ site mercadolivre.com é a plataforma de consumo com o maior número de visitantes únicos nos países onde opera. Desde 2007, a companhia tem capital aberto na Nasdaq (NASDAQ: MELI), bolsa de valores americana (LINKEDIN MERCADO LIVRE, 2020).

De acordo com a B2 Rocket (2021), o Mercado Livre é o e-marketplace mais acessado do Brasil, assumindo também a posição de empresa mais valiosa da América Latina. O site conta com 300 milhões de usuários cadastrados, e chega a registrar mais de 10 compras a cada segundo. Segundo o próprio Mercado Livre (2021), a plataforma é líder em comércio eletrônico na América Latina, contando com milhões de vendedores e compradores que fazem transações de diversos produtos e serviços diariamente. A empresa opera em 18 países da América Latina, sendo líder no setor de comércio eletrônico no Brasil, Argentina, Chile, Colômbia, Costa Rica, Equador, México, Peru, Uruguai e Venezuela, por número de visitas no site.

O próprio site do Mercado Livre (2021) afirma que o e-marketplace é uma plataforma de comércio eletrônico com um ecossistema inovador que está sempre em busca das melhores soluções e integrações, que permitem milhões de usuários negociarem uma grande variedade de serviços e produtos da forma mais fácil, eficiente e segura.

Segundo a Forbes (2021), o Mercado Livre é líder em seu segmento, auxiliando diretamente o crescimento econômico do país. A plataforma conhecida como o maior portal latino-americano de comércio eletrônico e pagamentos teve uma receita líquida de US $\$ 1,7$ bilhões entre abril e junho de 2021. Tal faturamento superou as projeções feitas por analistas e segue crescendo cada vez mais com os "efeitos pandemia". A companhia divulgou um lucro líquido de US $\$ 68,2$ milhões no segundo trimestre de 2021. O Mercado Livre (2021) anunciou seus resultados do primeiro trimestre de 2021, fechando com uma receita líquida de US $\$ 1,4$ bilhões.

Os números divulgados pelo e-marketplace Mercado Livre (2021) indicam 69,8 milhões de usuários únicos ativos durante o primeiro trimestre de 2021, 
sendo um aumento de $61,6 \%$ em relação ao mesmo período de 2020 . Foram registrados 299,5 milhões de anúncios em sua plataforma, e isso se deve ao aumento de vendedores no e-marketplace, que conta com quase 1 milhão de vendedores com vendas realizadas no trimestre citado. O Mercado Envios relatou que 208,1 milhões de itens foram enviados neste período.

Os números apresentados acima favorecem a pesquisa, tendo em vista que, existem milhões de produtos anunciados no site e quando o usuário busca um produto dentro da plataforma, aparecem diversos anúncios do mesmo produto. O que leva o consumidor a escolher aquele produto de determinado comprador? O preço? A reputação do vendedor? A persuasão do anúncio? O custo-benefício? A quantidade de vendas que o anúncio já teve? A entrega no mesmo dia da compra? 


\section{Métodos e procedimentos de coleta e de análise de dados do estudo}

Este capítulo tem como objetivo apresentar como foram dirigidas as pesquisas deste trabalho.

\subsection{Tipo de Pesquisa}

Para este trabalho, foi realizada uma pesquisa quantitativa com caráter exploratório e descritivo.

A pesquisa exploratória, segundo Gil (2002), tem como objetivo buscar a maior familiaridade possível dos dados procurados junto ao problema do estudo, buscando deixá-lo mais compreensível através das respostas adquiridas.

As pesquisas descritivas, ainda para Gil (2002), têm como propósito apresentar as características de certa população ou fenômeno, até mesmo, estabelecendo relações entre as variáveis.

A pesquisa baseou-se no levantamento de dados por meio da análise quantitativa, solicitando informações a um grupo significativo de pessoas para obter resultados referentes aos dados coletados (GIL, 2002).

\subsection{População e amostra}

A coleta de dados ocorreu por meio de um questionário que obteve um total de 142 respostas, provenientes do público masculino e feminino de diferentes faixas etárias, residentes nas regiões Sul, Sudeste e Centro-Oeste.

Das respostas obtidas, 114 se enquadram nos requisitos do estudo por comprarem produtos com determinada frequência no Mercado Livre. As outras 28 pessoas, ou nunca compraram qualquer produto/serviço pela internet, ou não conhecem o site (e-marketplace) Mercado Livre, ou não compram com frequência produtos na plataforma. 
Com isso, foram descartadas 28 respostas e analisados 114 resultados válidos.

\subsection{Coleta de dados}

Os dados foram coletados a partir de uma pesquisa quantitativa que possibilitou uma grande quantidade de respostas que auxiliaram na conclusão do trabalho. O instrumento utilizado foi o Google Forms, que de acordo com o próprio Google (2021), possibilita a criação de formulários para a coleta de informações em pequenas, médias ou grandes quantidades gratuitamente.

A pesquisa contém 14 perguntas, divididas em 2 etapas. A primeira etapa, a fim de identificar o perfil de compra e localização do respondente, contém perguntas demográficas e de caráter pessoal. Essa etapa tem como objetivo entender o quanto o consumidor utiliza a internet e o Mercado livre para fazer compras. Vale ressaltar que os respondentes que nunca realizaram uma compra na internet ou no Mercado Livre, não foram encaminhados para a segunda etapa.

$\mathrm{Na}$ segunda etapa, foram elaboradas questões que auxiliam na identificação do comportamento de compra do respondente dentro da plataforma, permitindo uma análise do perfil de consumidor que o usuário se enquadra, analisando as principais questões que o levam a escolher o $e$ marketplace em questão para fazer uma compra ou desistirem da ação, principais avaliações antes de adquirir um produto/serviço, avaliação do processo de compra e recomendações. A coleta de dados tem como base o $e$ marketplace Mercado Livre.

\subsection{Limitações do Método}

De acordo com o método utilizado na pesquisa quantitativa, devem ser consideradas as seguintes limitações:

- Com as respostas adquiridas e com o levantamento de dados com as tais, não devem ser consideradas como base para o futuro, tendo em vista a constante mudança no comportamento de compra do consumidor. De acordo com Kotler e Keller (2012), conforme os anos passam, os comportamentos de cada 
consumidor se alteram de acordo com suas necessidades e preferências.

- Os resultados obtidos e apresentados não devem ser generalizados, tendo em vista que foram levantadas informações de uma pequena amostra de pessoas comparado à quantidade de visitas/compras feitas diariamente no site. 


\section{Apresentação e análise dos resultados}

Este capítulo apresenta e discute os principais resultados alcançados, analisa e discute suas implicações e produz sugestões sobre o estudo previamente selecionado.

\subsection{Perfil dos respondentes}

\subsubsection{Sexo}

O gráfico 1 representa o sexo dos respondentes, sendo declarado que $58,5 \%$ representam o gênero masculino e $41,5 \%$ o gênero feminino.

\section{Gráfico 1: Qual seu sexo?}

Contagem de Qual seu sexo?

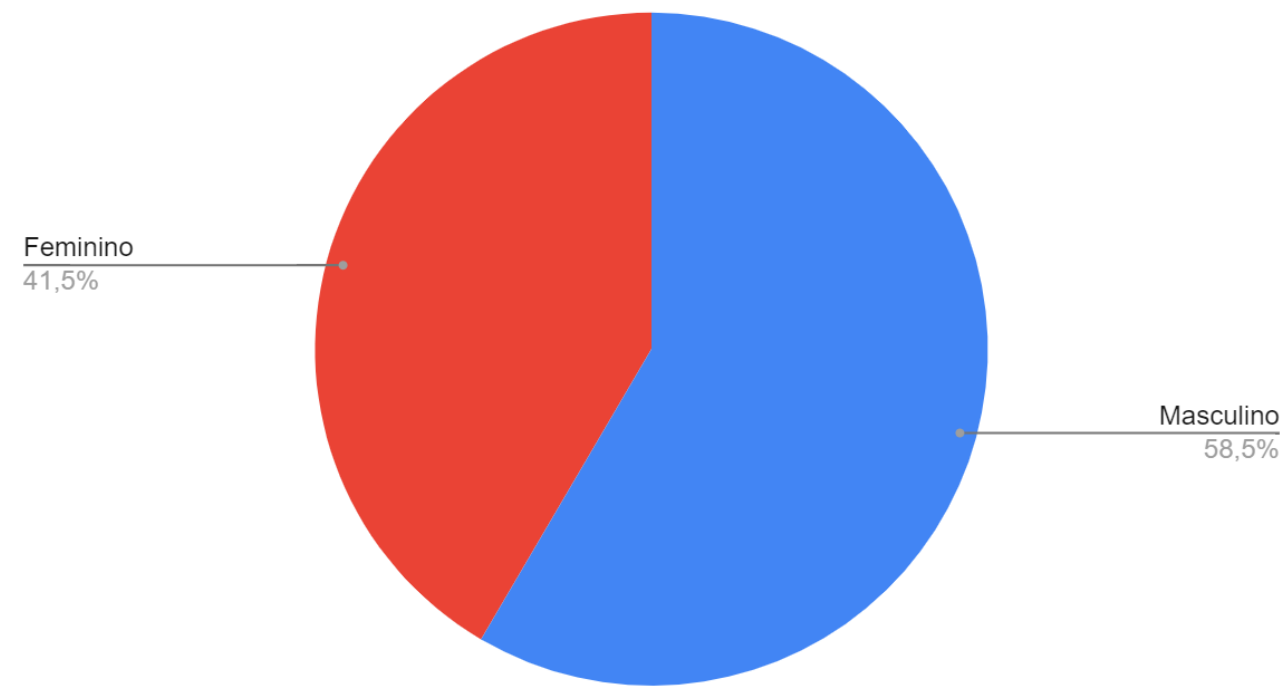

Fonte: Dados da pesquisa - Google Forms (2021) 


\subsubsection{Idade}

Conforme sinaliza o gráfico 2, a maioria dos respondentes são representados pelo público com idade entre 18 e 24 anos (35,9\%), logo em seguida o público de 25 a 31 anos $(21,1 \%)$ se mostrou presente nas respostas. A pesquisa contou também com respostas do público de 32 a 38 anos (18,3\%), 39 a 45 anos (7,0\%), 60 anos ou mais (6,3\%), 46 a 52 anos (4,9\%), 53 a 59 anos $(4,2 \%)$ e até 17 anos (2,1\%).

\section{Gráfico 2: Qual sua Idade?}

\section{Contagem de Qual sua idade?}

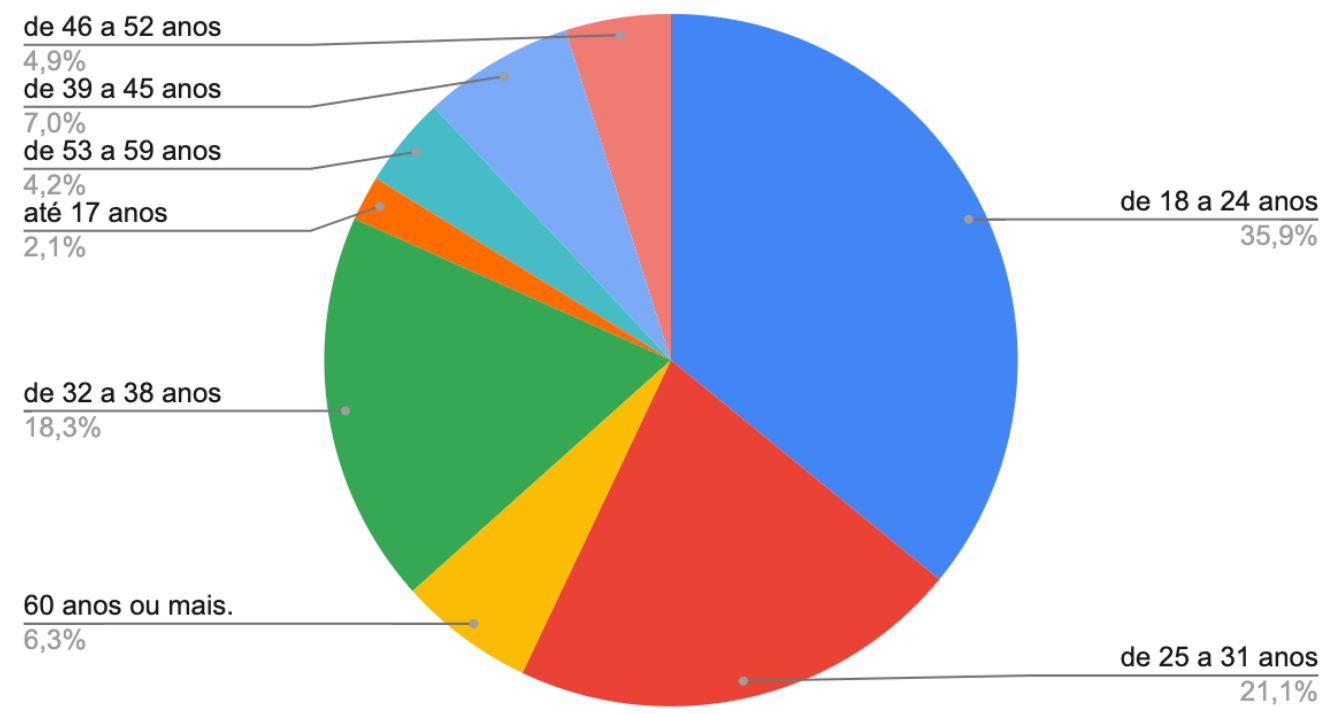

Fonte: Dados da pesquisa - Google Forms (2021) 


\subsubsection{Região em que residem}

O gráfico 3 contém as regiões do Brasil em que os respondentes moram. O questionário foi aberto para todas as regiões, mas apenas contou com respostas de pessoas da região Sudeste (83,8\%), Sul $(9,9 \%)$ e Centro-Oeste $(6,3 \%)$. Esse fato se deve à distribuição do questionário que alcançou apenas pessoas que residem nessas regiões.

\section{Gráfico 3: Em que região do Brasil você mora?}

\section{Contagem de Em que região do Brasil você mora?}

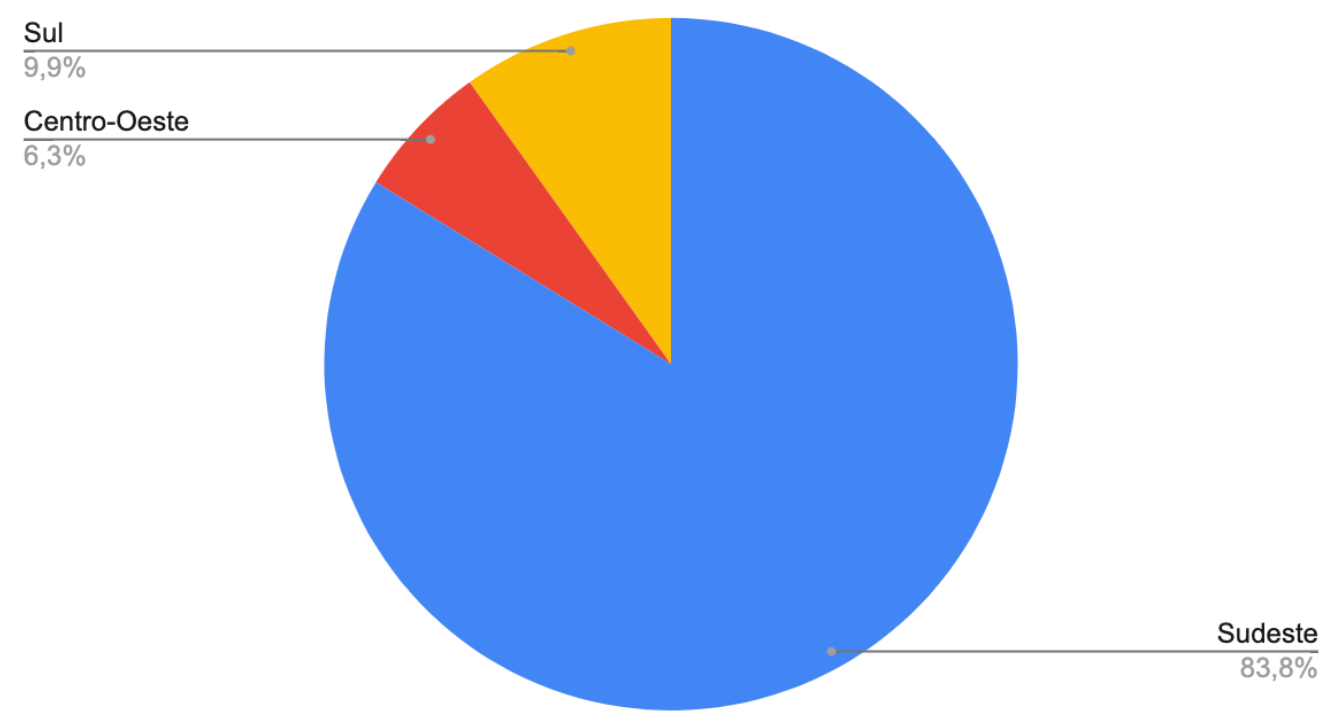

Fonte: Dados da pesquisa - Google Forms (2021) 


\subsubsection{Consumidores de e-commerce}

De acordo com o gráfico 4, observa-se que a maioria dos respondentes compra entre 1 e 2 vezes ao mês qualquer tipo de produto/serviço na internet $(47,2 \%)$, logo em seguida as pessoas que compram entre 3 e 4 vezes $(31,7 \%)$, as que compram entre 5 e 6 vezes (16,2\%) e entre 7 e 8 vezes (3,5\%). Por conterem um número muito pequeno de respondentes, o "nunca comprei" $(0,7 \%)$ que é representado pela cor verde e o "compro mais de 8 vezes por mês" $(0,7 \%)$, representado pela cor azul claro, não tiveram legendas no gráfico.

\section{Gráfico 4: Quantas vezes, em média, você compra qualquer produto ou serviço pela Internet?}

\section{Contagem de Quantas vezes, em média, você compra qualquer produto ou serviço pela Internet?}

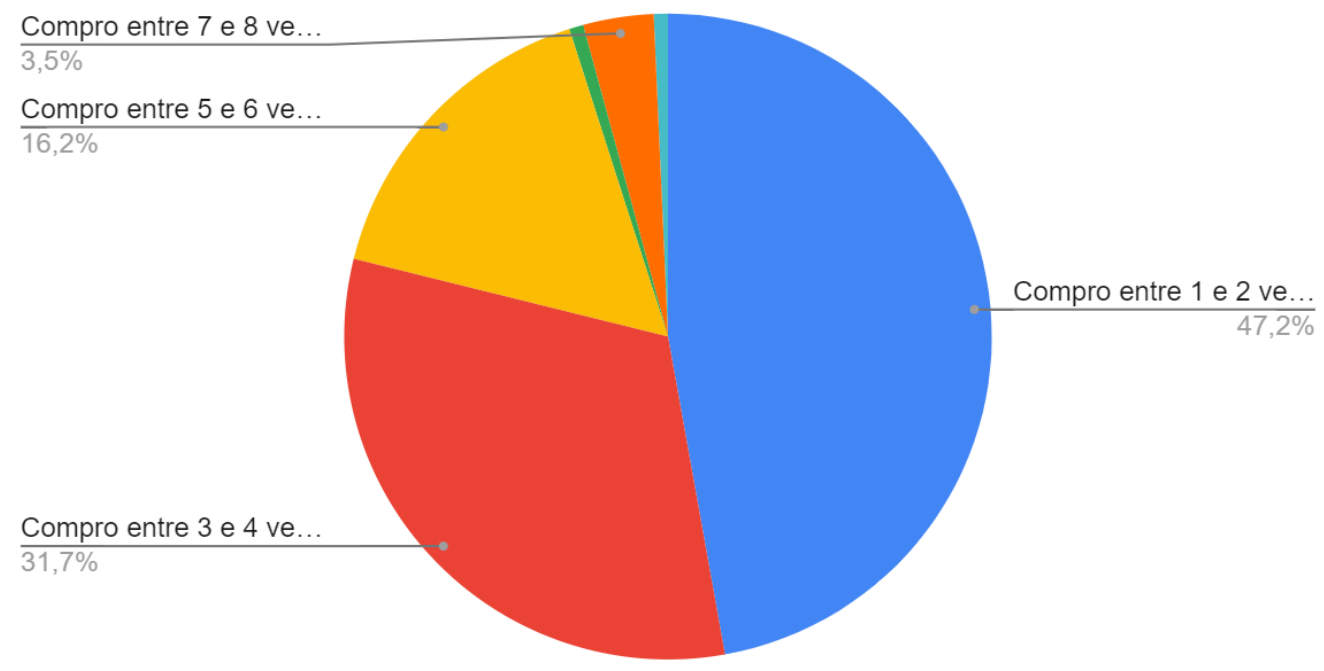

Fonte: Dados da pesquisa - Google Forms (2021) 


\subsubsection{Consumidores de e-commerce na pandemia}

Com o gráfico 5, podemos observar o aumento no número de pessoas que disseram ser influenciadas pela pandemia a comprarem mais pela internet. $47,9 \%$ dos respondentes afirmaram que a pandemia do COVID-19 à influenciou muito a adquirir produtos online. Logo em seguida, com $26,1 \%$, vêm os respondentes que assinalaram que foram razoavelmente influenciados. Apenas $7,7 \%$ das pessoas não foram influenciadas.

Pode-se concluir que o fato de as pessoas passarem mais tempo em casa cumprindo a quarentena as influenciou a adquirir mais produtos na internet.

\section{Gráfico 5: A pandemia do COVID-19 te influenciou a realizar mais compras} através da internet?

\section{Contagem de A pandemia do COVID-19 te influenciou a realizar mais compras através da internet?}

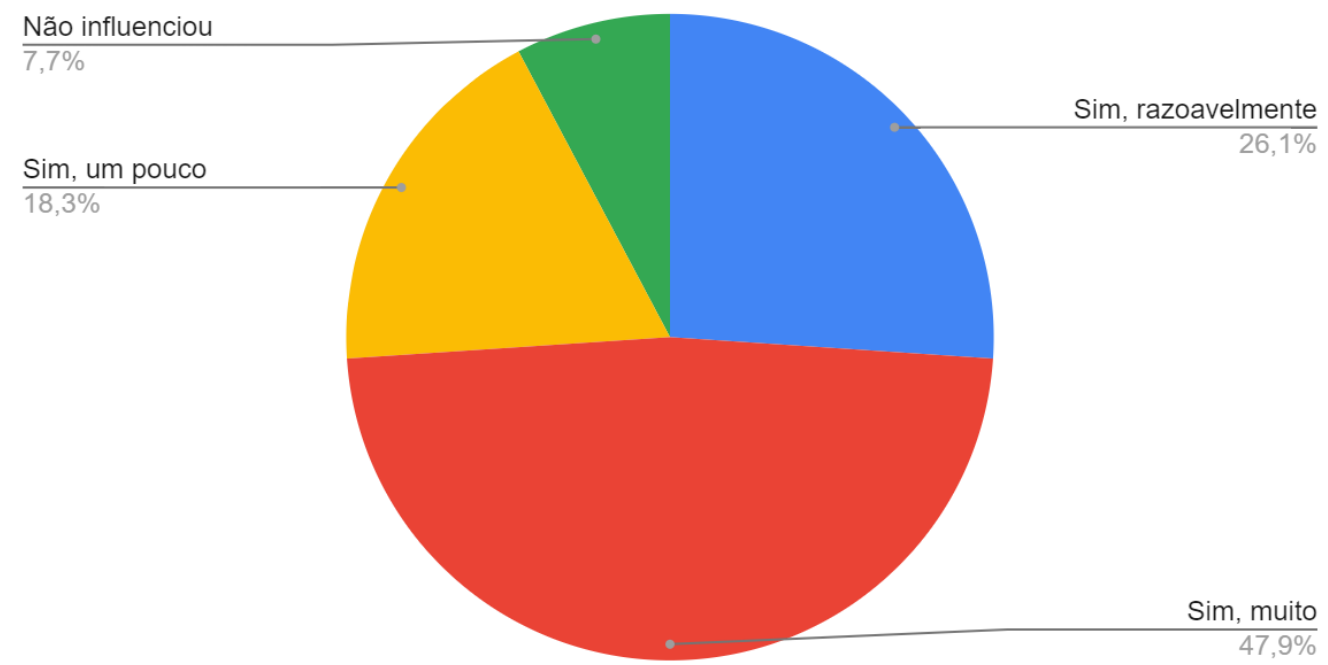

Fonte: Dados da pesquisa - Google Forms (2021) 


\subsubsection{Consumidores do e-marketplace}

Conforme o gráfico 6 , observa-se que $56,3 \%$ dos respondentes compram entre 1 e 2 vezes por mês, 17,6\% compram entre 3 e 4 vezes por mês e 0,7\% compram entre 7 e 8 vezes por mês qualquer produto ou serviço no site do mercado Livre, sendo esse o público cujo resultado será analisado. Os respondentes que nunca compram com frequência no Mercado Livre $(25,4 \%)$ foram retirados da pesquisa e não avançando para a segunda parte.

\section{Gráfico 6: Com que frequência você realiza compras por meio do Mercado}

livre?

\section{Contagem de Com que frequência você realiza compras por meio do Mercado Livre?}

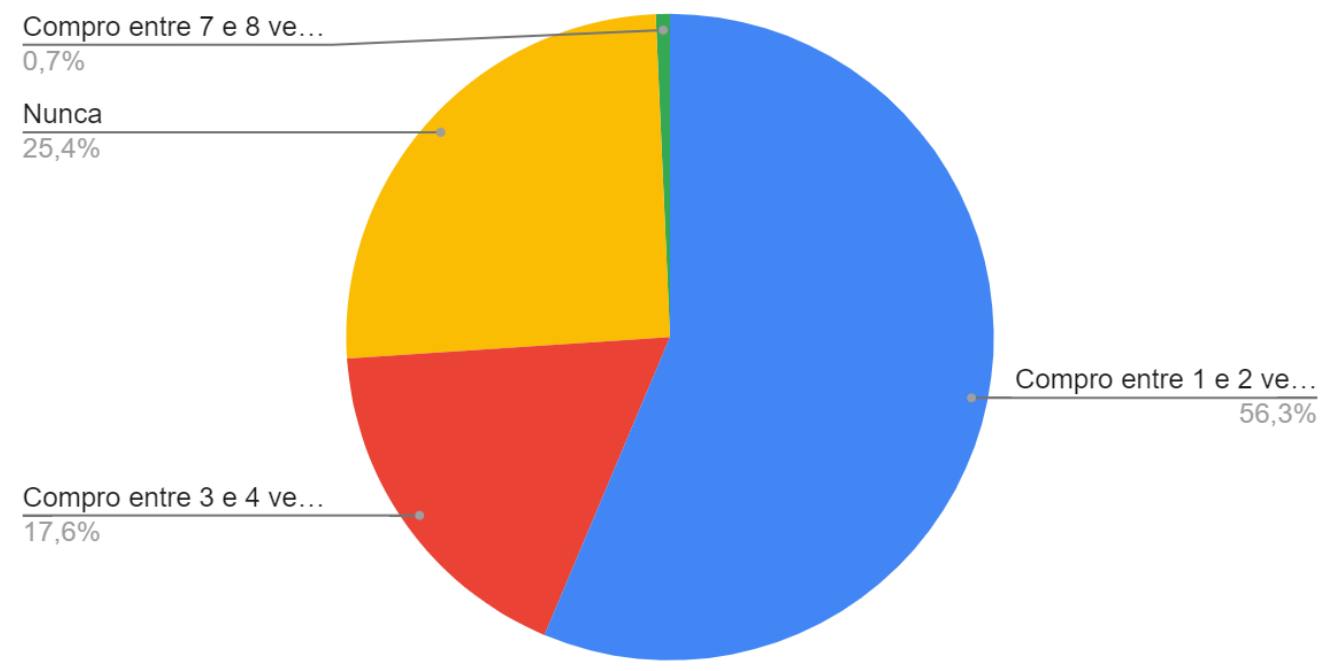

Fonte: Dados da pesquisa - Google Forms (2021)

\subsection{Análise dos resultados}

\subsubsection{Como conheceu o Mercado Livre}

Entender essa variável é de extrema importância para uma empresa, tendo em vista que é por meio dela que se entende como o consumidor chega até a plataforma e onde o marketing deve ser mais explorado. 
Como citado no tópico 4.1.5, a partir daqui apenas respondentes que adquirem a partir de 1 a 2 produtos/serviços por mês dentro da plataforma seguiram no questionário.

Como observado no gráfico 6 , a grande maioria dos compradores do Mercado Livre conheceu a empresa por meio da recomendação de terceiros $(41,2 \%)$, e em segundo lugar vieram os que conheceram através das ferramentas de busca (como Google, Bing etc.) sendo representados por 35,1\%. Em seguida vêm os que conheceram por meio de anúncios em sites (17,5\%) e depois os que descobriram por meio de anúncio em TV (6,1\%).

Com as informações apuradas, percebe-se a grande quantidade de consumidores satisfeitos com o serviço prestado pela empresa e recomendam para o próximo, pois o boca-a-boca representa a maior ferramenta de marketing da plataforma. O número pequeno de respostas em "Anúncio em TV" pode ser devido ao baixo investimento da empresa nesse meio.

\section{Gráfico 6: Como conheceu o e-marketplace Mercado Livre?}

\section{Contagem de Como conheceu o e-marketplace Mercado Livre?}

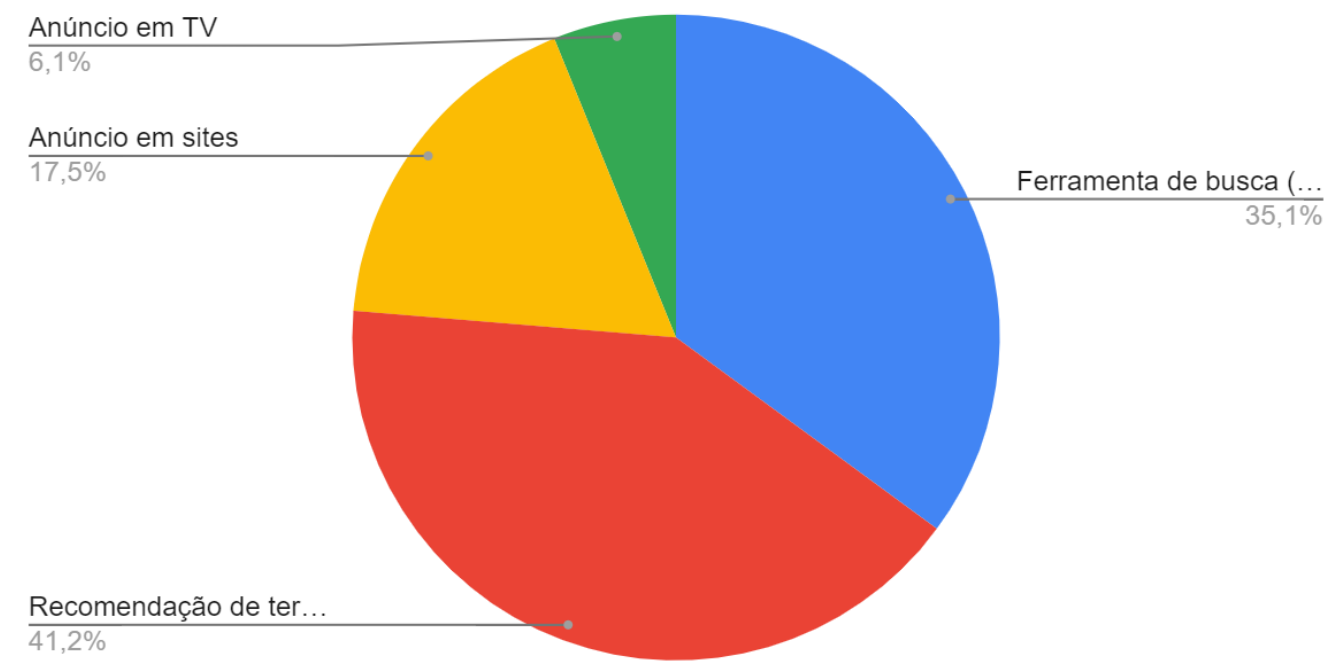

Fonte: Dados da pesquisa - Google Forms (2021) 


\subsubsection{O que faz escolher o Mercado Livre para a compra de um produto}

A segunda pergunta refere-se ao que leva o respondente a escolher o site do Mercado Livre para realizar a compra de um produto. O objetivo principal dessa pergunta era entender o que faz o consumidor querer adquirir produtos na plataforma. As opções de resposta foram: a grande quantidade de anúncios do mesmo produto, a segurança do site, preços baratos, frete grátis, possibilidade de compra de produtos que chegarão no dia seguinte e programa de benefícios Mercado Pontos. Das opções disponíveis, os respondentes tiveram total liberdade para votarem em quantas opções julgassem necessárias, e podemos destacar que de todas as respostas obtidas nessa questão, $73,7 \%$ dos cliques foram em "a grande quantidade de anúncios do mesmo produto", levando a entender que os consumidores gostam da liberdade de comparar os anúncios do site antes de escolher em qual irão de fato realizar a compra. A própria plataforma aproveita e reconhece este atributo, adicionando a opção de filtros através de preço, quais anúncios possuem frete grátis, com parcelamento, localização da loja vendedora etc.

$72,8 \%$ destacaram a segurança do site, e isso apresenta que os compradores confiam e reconhecem a credibilidade do site. De acordo com Alex Moro (2020), muitas pessoas nunca realizaram uma compra no Mercado Livre por medo de golpes por conta de a plataforma aceitar vendedores informais e que utilizam apenas o CPF para se identificar, e isso acaba prejudicando sua reputação. A empresa mais valiosa da América Latina deveria deixar mais claro sobre a sua segurança e que todos os compradores irão receber seus produtos do jeito em que foram anunciados ou receberão o reembolso.

O "programa de benefícios Mercado Pontos" teve apenas $14 \%$, podendo concluir que os respondentes não se importam muito com as vantagens. A plataforma deveria melhorar as recompensas ou até mesmo deixá-las mais nítidas, visando uma fidelização do consumidor do e-marketplace. 
Gráfico 7: 0 que te faz escolher o Mercado livre para realizar a compra de um produto?

\section{Contagem de $\mathrm{O}$ que te faz escolher o Mercado Livre para realizar a compra de um produto? (Sinalizar quantas opções forem necessárias)}

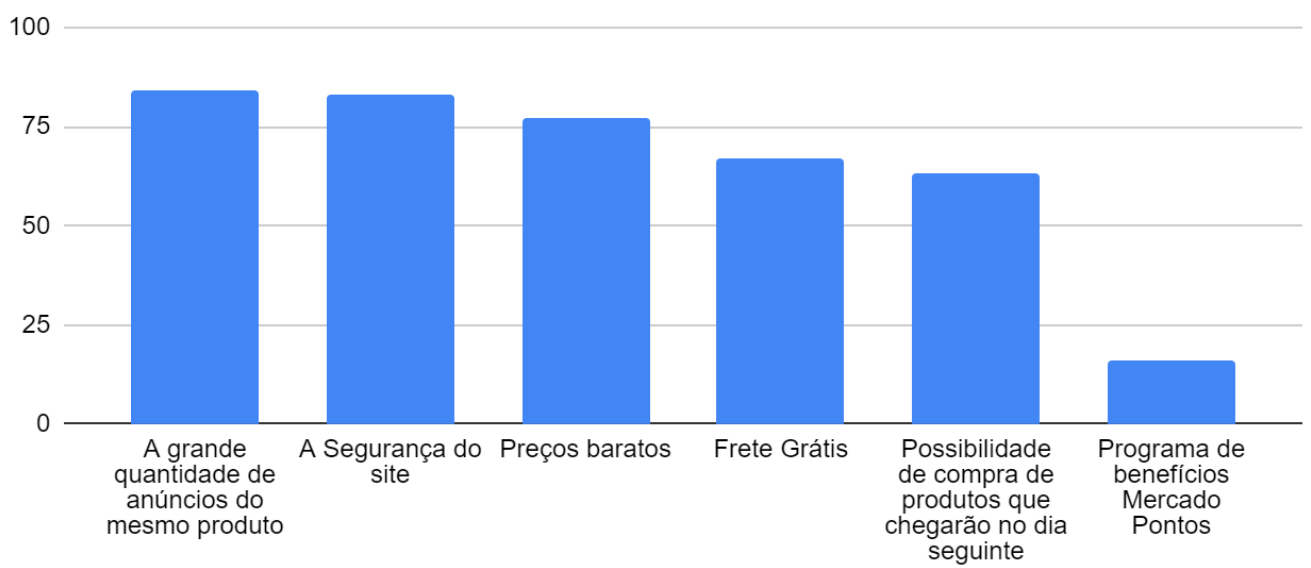

O que te faz escolher o Mercado Livre para realizar a compra de um produto? (Sinalizar quantas opções fo...

Fonte: Dados da pesquisa - Google Forms (2021)

\subsubsection{Avaliação dos anunciantes da plataforma}

O objetivo deste tópico é entender como o consumidor filtra a escolha de um anúncio após realizar a pesquisa de um produto nas buscas e se deparar com diversos anúncios semelhantes. Todas as opções poderiam ser avaliadas com nada importante, pouco importante, importante, muito importante e extremamente importante.

\subsubsection{Preço}

O gráfico 8 sinaliza a influência do preço na escolha do anúncio. 64,9\% avaliaram o preço como extremamente importante, mostrando a grande importância de se ter um preço competitivo dentro da plataforma para se destacar perante os concorrentes. O muito importante contou com 19,3\% de avaliação, importante com $14 \%$ e pouco importante $1,7 \%$.

O Mercado Livre deve aproveitar a grande importância dos compradores ao fator preço, buscando ofertas eventuais e descontos nas taxas cobradas em cima dos vendedores caso eles abaixem o preço do anúncio. 
Gráfico 8: Como você avaliaria a possibilidade de compra de um produto de determinado vendedor (ou empresa vendedora) dentro do Mercado Livre? [Preço]

Contagem de Como você avaliaria a possibilidade de compra de um produto de determinado vendedor (ou empresa vendedora) dentro do Mercado Livre? [Preço]

80

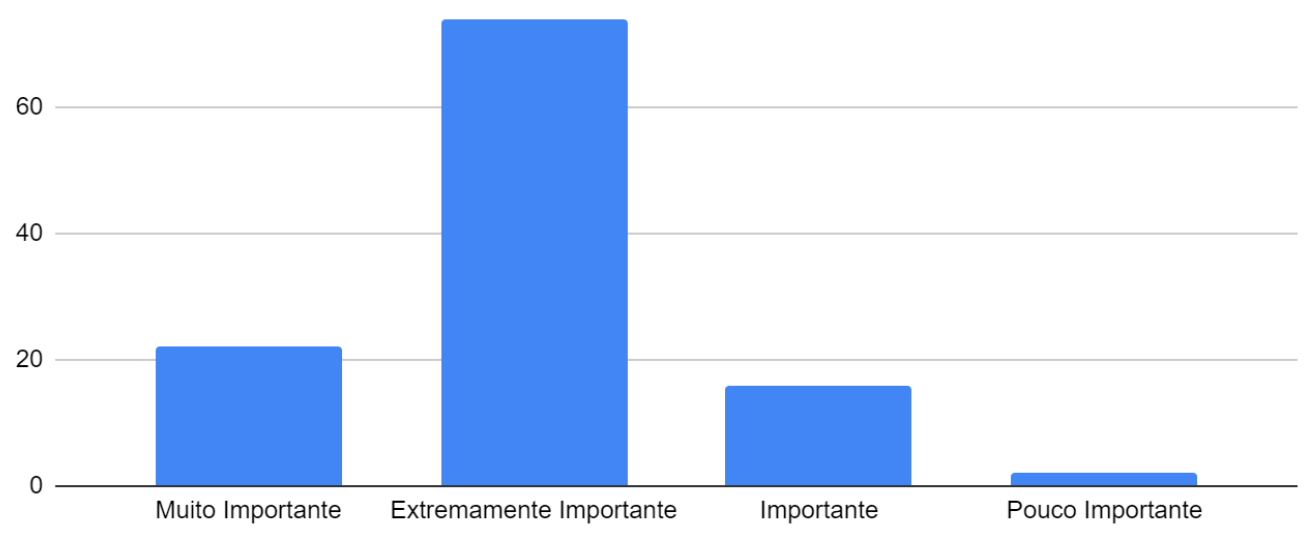

Contagem de Como você avaliaria a possibilidade de compra de um produto de determinado vendedor (ou e...

Fonte: Dados da pesquisa - Google Forms (2021) 


\subsubsection{Marca}

A marca também se mostrou extremamente importante quando se vai fazer a compra de um produto na plataforma, contando com 39,5\% de avaliações. O anúncio de um produto de marca pode, sim, influenciar o consumidor a comprá-lo. Logo em seguida vem o "importante" com 31,6\%, muito importante com $21,1 \%$ e pouco importante contando com $7,9 \%$.

Colocar os primeiros anúncios da página com produtos de marca quando se procura por algo, pode influenciar a compra do produto.

\section{Gráfico 9: Como você avaliaria a possibilidade de compra de um produto de determinado vendedor (ou empresa vendedora) dentro do Mercado Livre? [Marca]}

\section{Contagem de Como você avaliaria a possibilidade de compra de um produto de determinado vendedor (ou empresa vendedora) dentro do Mercado Livre? [Marca]}

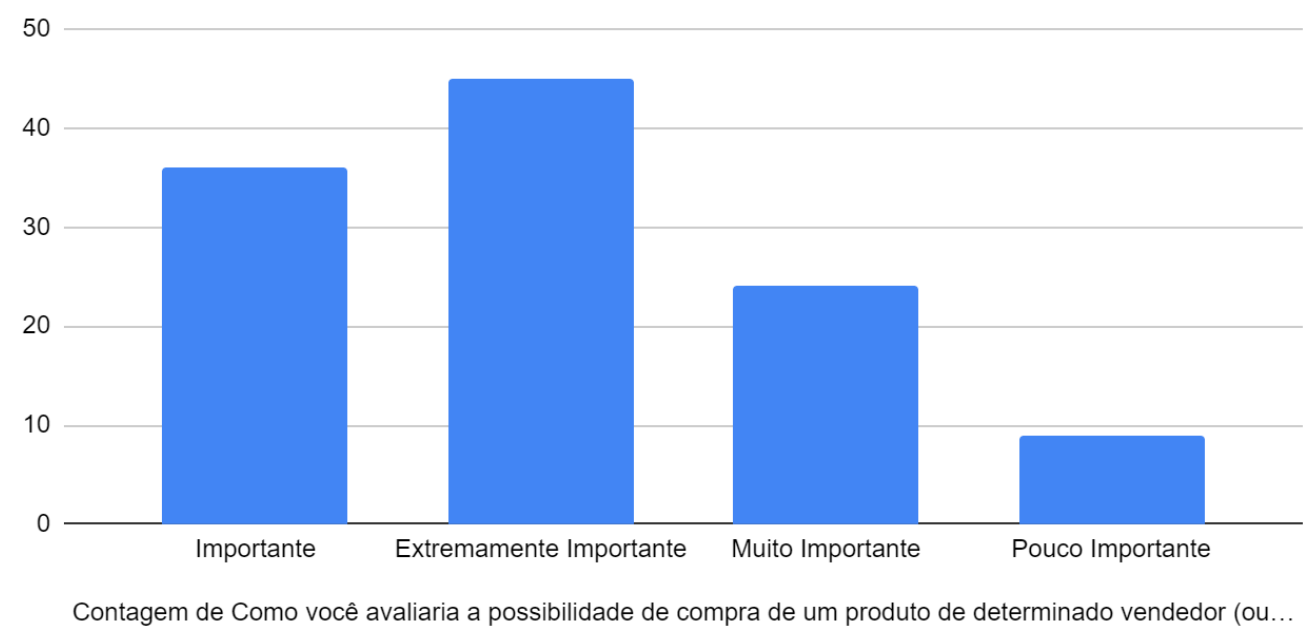

Fonte: Dados da pesquisa - Google Forms (2021) 


\subsubsection{Reputação do vendedor}

De todos os tópicos da avaliação dos anunciantes na plataforma, a reputação do vendedor foi o que mais teve votos em "extremamente importante", contando com a avaliação de $74,6 \%$ dos respondentes. O "muito importante" contou com 16,7\%, "importante" teve 6,1\% e "pouco importante", 2,6\%.

Esses dados levam a entender que os consumidores estão em busca de vendedores que são bem avaliados dentro da plataforma, cumprindo prazos, não cancelando a compra, respondem com frequência e realizam troca dos produtos.

Gráfico 10: Como você avaliaria a possibilidade de compra de um produto de determinado vendedor (ou empresa vendedora) dentro do Mercado Livre? [Reputação do vendedor]

\section{Contagem de Como você avaliaria a possibilidade de compra de um produto de determinado vendedor (ou empresa vendedora) dentro do Mercado Livre? [Reputação do Vendedor]}

100

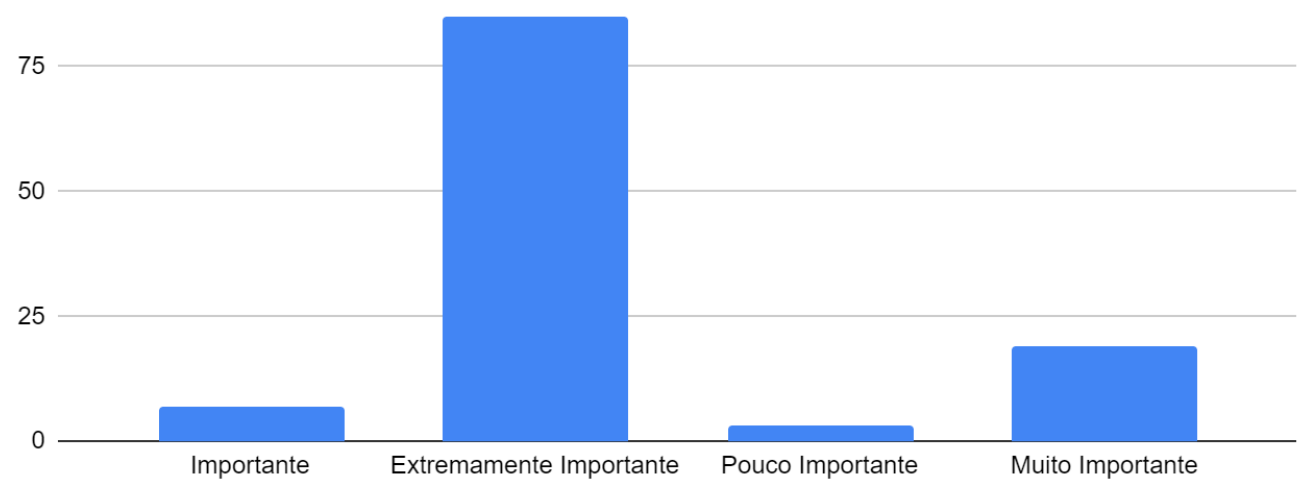

Contagem de Como você avaliaria a possibilidade de compra de um produto de determinado vendedor (ou e...

Fonte: Dados da pesquisa - Google Forms (2021) 


\subsubsection{Quantidade de vendas que o anúncio possui}

É possível ver que os respondentes também se importam com a quantidade de produtos vendidos do anúncio. A pergunta em questão obteve $39,5 \%$ de avaliações em extremamente importante. As outras opções contaram com $27,2 \%$ em muito importante e em importante, e pouco importante contou com $6,1 \%$.

\section{Gráfico 11: Como você avaliaria a possibilidade de compra de um produto de determinado vendedor (ou empresa vendedora) dentro do Mercado Livre? [Quantidade de vendas que o anúncio possui]}

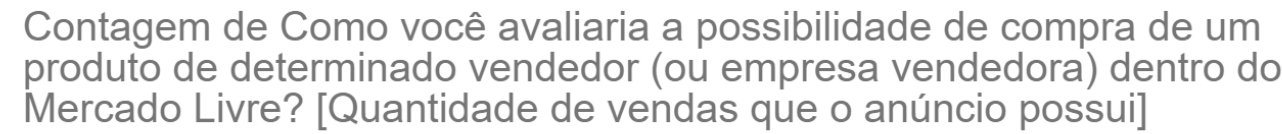
Mercado Livre? [Quantidade de vendas que o anúncio possui]

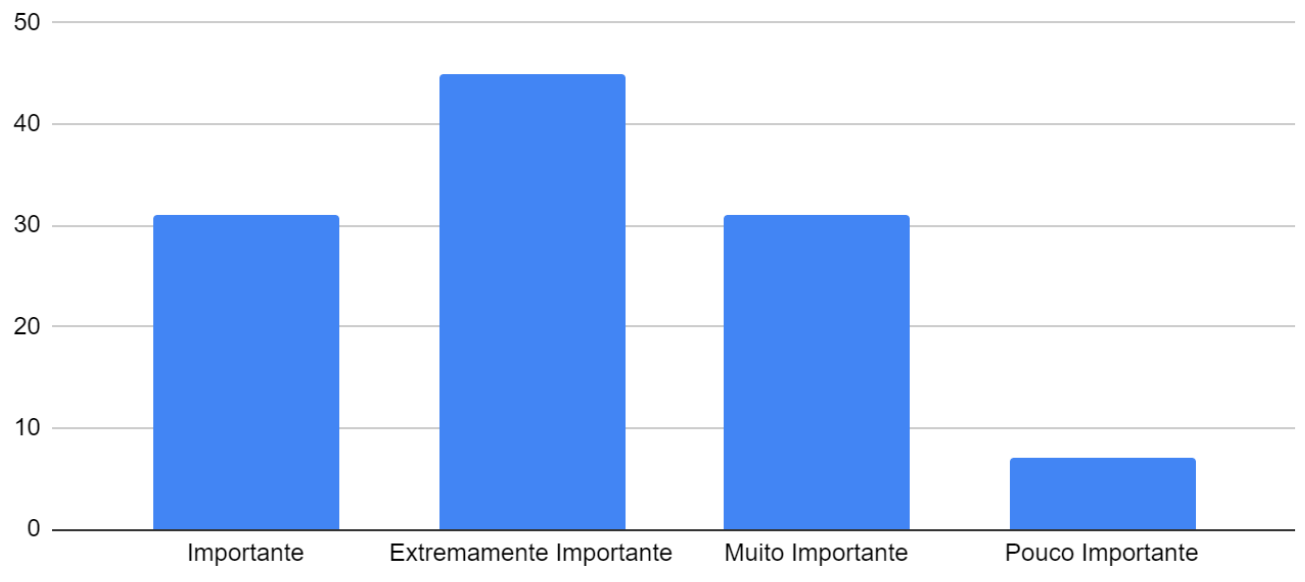

Contagem de Como você avaliaria a possibilidade de compra de um produto de determinado vendedor (ou emp...

Fonte: Dados da pesquisa - Google Forms (2021) 


\subsubsection{Frete Grátis}

O gráfico 12 sinaliza a avaliação dos respondentes quando o assunto é frete grátis. Foi a primeira pergunta na avaliação o qual não contou com a maior avaliação em "extremamente importante". A maior parte dos consumidores responderam com "importante", representando 28,9\%. "Extremamente importante" contou com 26,3\%, "muito importante" com 21,9\%, "pouco importante" com 20,2\%. A opção "nada importante" contou com 2,6\%.

A plataforma deveria buscar oferecer frete grátis na maior quantidade possível de anúncios, tendo em vista que certas regiões acabam sofrendo com o enorme valor do frete, as vezes pagando mais no transporte do que no produto em si. O valor do frete pode levar o potencial comprador a desistir da compra na plataforma e optar por outro site com preços menores.

Gráfico 12: Como você avaliaria a possibilidade de compra de um produto de determinado vendedor (ou empresa vendedora) dentro do Mercado

\section{Livre? [Frete Grátis]}

\section{Contagem de Como você avaliaria a possibilidade de compra de um produto de determinado vendedor (ou empresa vendedora) dentro do Mercado Livre? [Frete Grátis]}

40

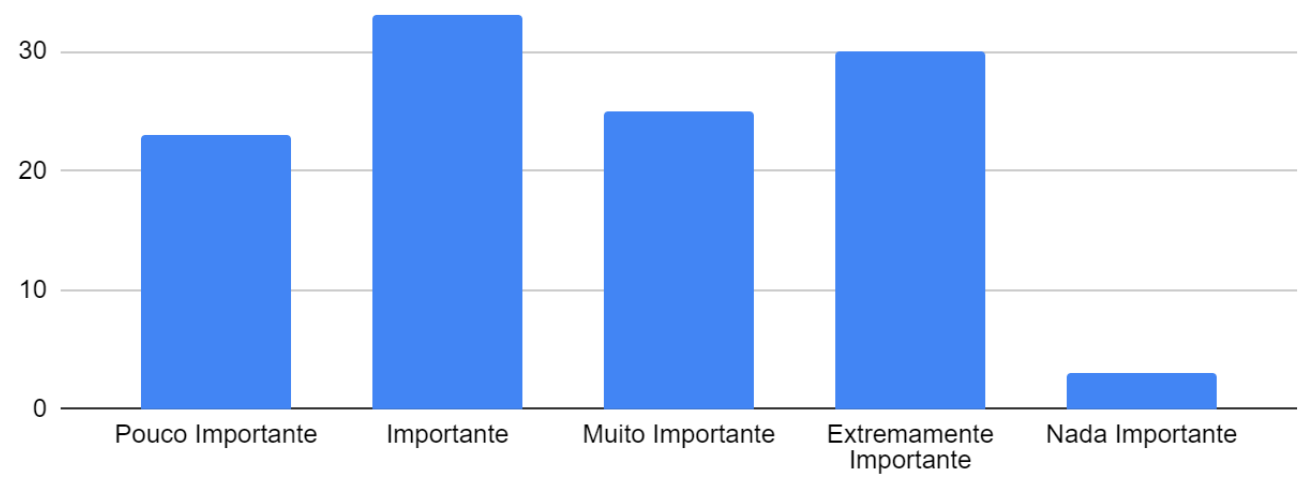

Contagem de Como você avaliaria a possibilidade de compra de um produto de determinado vendedor (o.

Fonte: Dados da pesquisa - Google Forms (2021) 


\subsubsection{Entrega do produto no dia seguinte após a compra}

Novamente a categoria "importante" contou com a maior avaliação, 37,7\% dos votos foram nessa categoria. Logo em seguida observamos o "pouco importante" com 25,4\%, "extremamente importante" com 16,7\%, "muito importante" com $14 \%$ e "nada importante" com 6,1\%.

Gráfico 13: Como você avaliaria a possibilidade de compra de um produto de determinado vendedor (ou empresa vendedora) dentro do Mercado Livre? [Entrega do produto no dia seguinte após a compra]

Contagem de Como você avaliaria a possibilidade de compra de um produto de determinado vendedor (ou empresa vendedora) dentro do Mercado Livre? [Entrega do produto no dia seguinte após a compra]

50

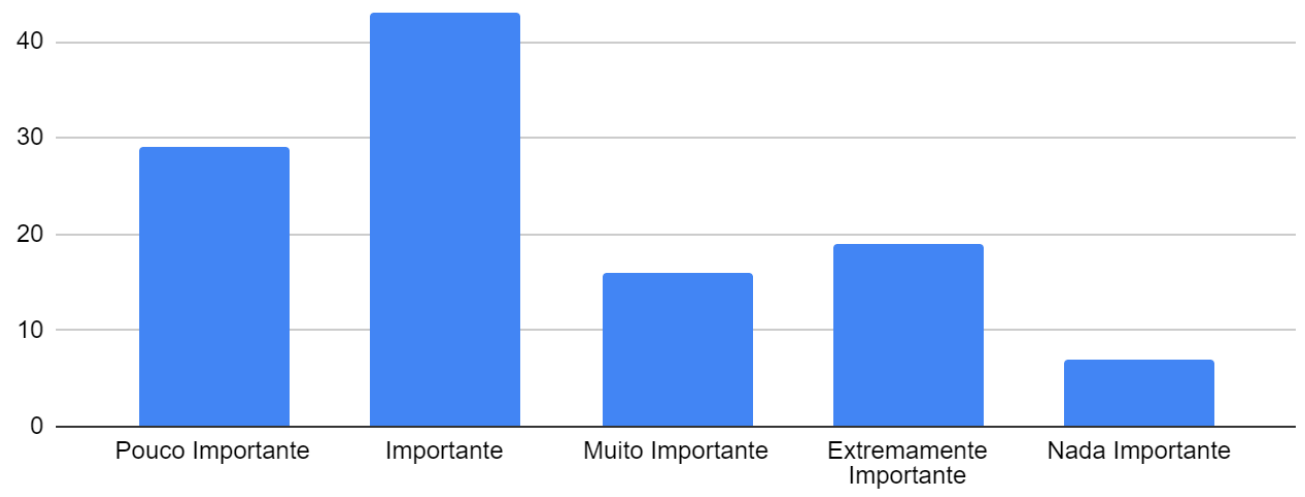

Contagem de Como você avaliaria a possibilidade de compra de um produto de determinado vendedor (ou em..

Fonte: Dados da pesquisa - Google Forms (2021) 


\subsubsection{Empresa vendedora conhecida (ex: Loja da Americanas.com dentro do Mercado Livre)}

Este foi o tópico onde o "pouco importante" mais teve votos e foi maior do que todas as outras 4 opções. A opção contou com 28,9\% das avaliações. Outro fator é que também foi o tópico que mais contou com votos na opção "nada importante", somando 8,77\% das avaliações. "Extremamente importante" contou com $28 \%$, "importante" com 17,5\% e "muito importante" com 16,7\%.

Analisando as respostas, podemos observar que a empresa vendedora ser conhecida é um diferencial para a realização da venda. Apesar de obter votos em "extremamente importante", foi a que mais teve votos em "pouco e importante" e "nada importante" dentre os tópicos disponíveis para a possibilidade de compra.

Gráfico 14: Como você avaliaria a possibilidade de compra de um produto de determinado vendedor (ou empresa vendedora) dentro do Mercado Livre? [Empresa vendedora conhecida (ex: Loja da Americanas.com dentro do Mercado livre)]

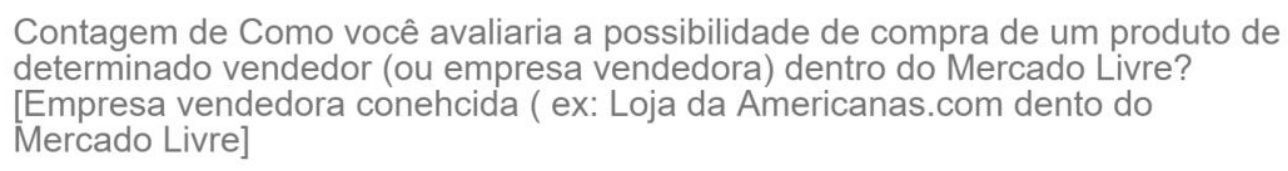

40

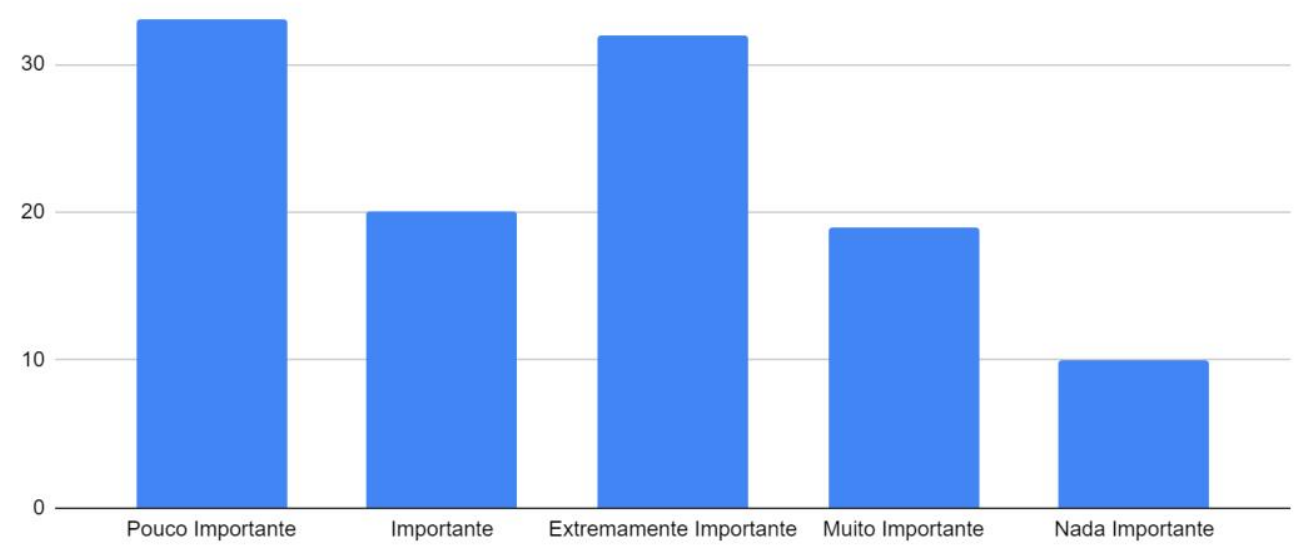

Contagem de Como você avaliaria a possibilidade de compra de um produto de determinado vendedor (ou empresa vendedor...

Fonte: Dados da pesquisa - Google Forms (2021) 


\subsubsection{Motivos da desistência de uma compra no Mercado Livre}

Quando se observa a quantidade de anúncios de um mesmo produto, os consumidores devem avaliá-los e desistir de determinados para poder escolher em qual irá realizar a compra. Esta pergunta tem o objetivo de entender quais os principais motivos que levam o consumidor a desconsiderar determinado anúncio. De acordo com o gráfico 15, a reputação do vendedor foi a que mais teve votos, contando com $57,1 \%$. O segundo mais votado foi o preço do frete, com $17,9 \%$, depois o preço alto do produto no anúncio $(9,8 \%)$, quantidade de vendas do anúncio $(7,1 \%)$, tempo para a entrega do produto $(4,5 \%)$ e dificuldade de contato com o vendedor (3,6\%).

Com os dados levantados e através de pesquisas no site, o Mercado Livre se importa ao máximo em ter anunciantes com a melhor reputação possível, tendo em vista que os anunciantes com reputações baixas botam em risco a segurança do site. De acordo com o próprio Mercado Livre (2021), anunciantes com reclamações, vendas canceladas e despachos atrasados acarretam uma queda na reputação, consequentemente, o vendedor perde visibilidade no site $\mathrm{e}$ sinaliza que $o$ anunciante não possui qualidade. A plataforma premia os que possuem boas reputações, posicionando-os no topo do site e recomendando-os. O site deve deixar sempre o mais claro possível a importância da reputação, sendo o melhor cartão de visita do vendedor e o que menos acarreta a desistência de uma compra.

O preço do frete também é um motivo que leva uma grande desistência de compras na plataforma. Como citado no tópico 4.2.3.5, o alto preço do transporte leva o consumidor a comprar produtos em sites concorrentes, tendo em vista que toda a logística é feita pela própria plataforma do Mercado Livre, e não pelo anunciante. 
Gráfico 15: O que te faz desistir de uma compra em uma plataforma como o Mercado Livre?

Contagem de $\mathrm{O}$ que te faz desistir de uma compra em uma plataforma como o Mercado Livre?

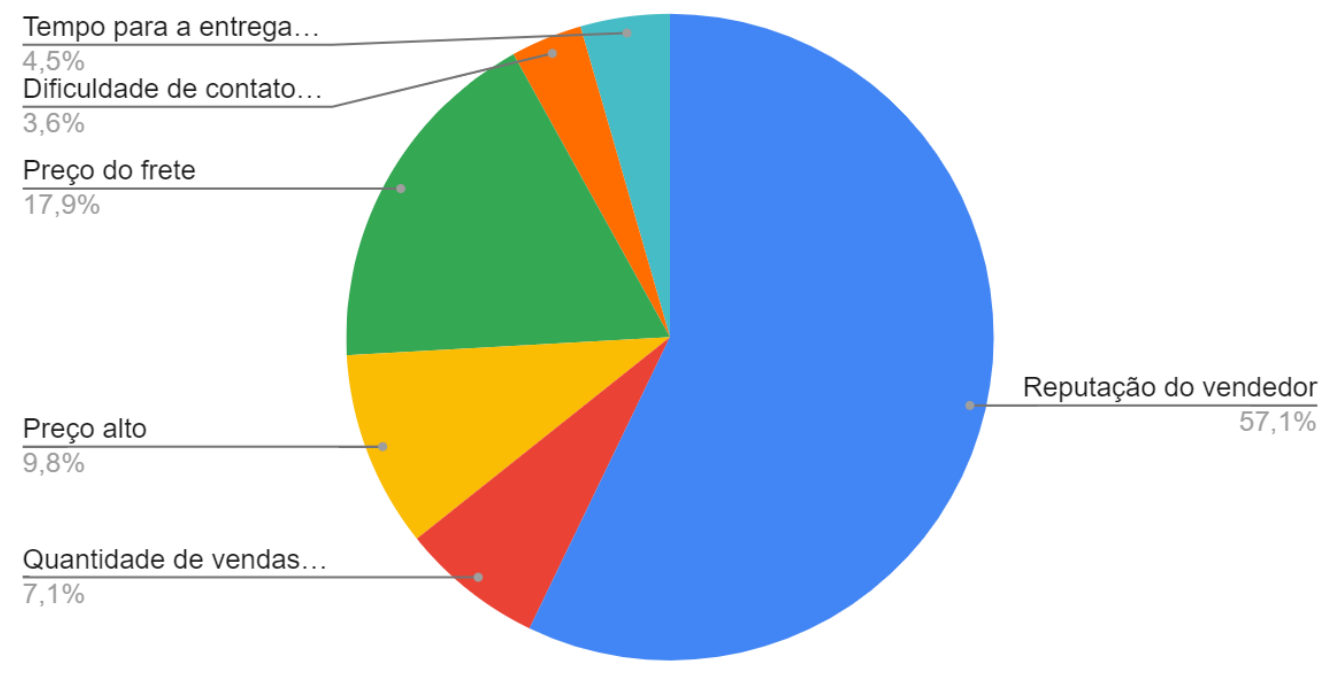

Fonte: Dados da pesquisa - Google Forms (2021) 


\subsubsection{Avaliação do processo de compra na plataforma}

O gráfico 16 mostra como os respondentes avaliam o processo de compra de produtos no Mercado Livre, podendo escolher entre as opções de muito fácil, fácil, normal, difícil, muito difícil. Dentre todas essas opções disponíveis, fácil contou com $44,7 \%$, muito fácil $33,3 \%$ e normal $21,9 \%$. Não houve votos em difícil ou muito difícil.

Esses dados revelam que a plataforma é de fácil entendimento, desde a escolha do produto até o pagamento e finalização do pedido.

Gráfico 16: Como você avalia o processo de compra no Mercado Livre?

Contagem de Como você avalia o processo de compra no Mercado Livre?

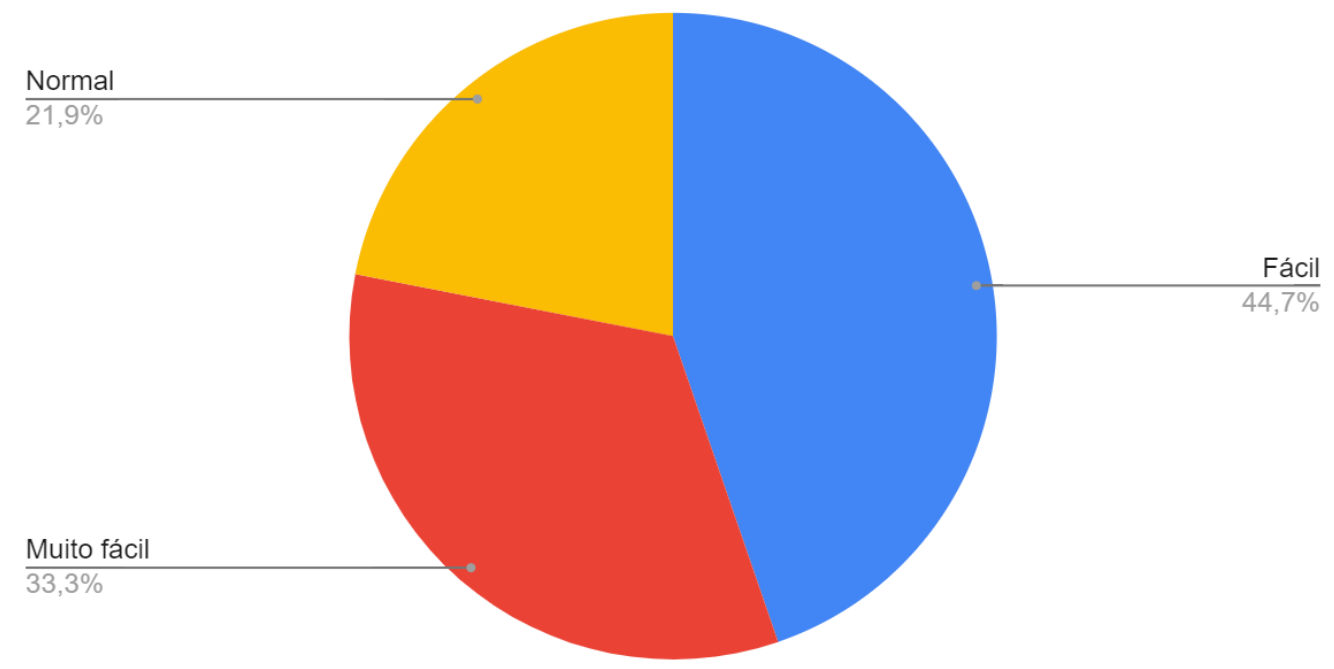

Fonte: Dados da pesquisa - Google Forms (2021) 


\subsubsection{Recomendação do Mercado Livre para outras pessoas}

É possível observar através do gráfico 17 que grande parte dos consumidores recomendariam a plataforma para outras pessoas. A opção sim recebeu $98,2 \%$ dos votos, enquanto a não apenas $0,9 \%$.

Isso fortalece o tópico 4.2.1, indicando que os consumidores da plataforma estão satisfeitos com a segurança e o serviço prestado pela mesma e fortalecem assim o famoso "boca-a-boca".

Gráfico 17: Você recomendaria o Mercado Livre para outras pessoas?

Contagem de Você recomendaria o Mercado Livre para outras pessoas?

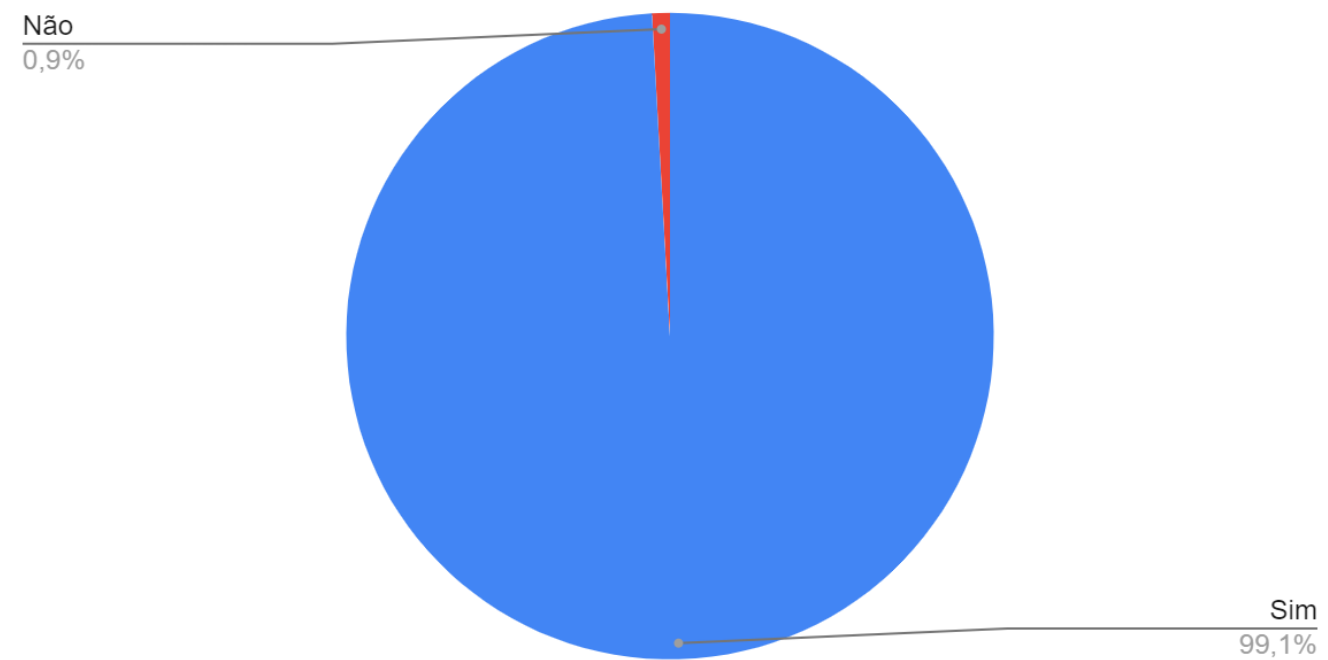

Fonte: Dados da pesquisa - Google Forms (2021) 


\section{Conclusões e recomendações para novos estudos}

O presente estudo teve como objetivo analisar o comportamento do consumidor do e-marketplace Mercado Livre, desde o motivo da escolha do site para a realização de uma compra até os motivos que o fazem decidir qual anúncio irá de fato mercar ou desistir. A coleta de dados foi realizada por meio de um formulário no site Google Forms que contou com 142 respostas, mas 28 pessoas tiveram que ser cortadas pelo fato de que nunca realizaram a compra de qualquer produto ou serviço pela internet, ou não conhecem a plataforma do Mercado Livre, ou não comprar pelo menos 1 ou 2 vezes por mês na plataforma. Tendo em vista esses dados, apenas 114 pessoas foram de fato analisadas a partir da segunda etapa, a qual tinha como objetivo entender o comportamento de compra do consumidor dentro da plataforma do Mercado Livre.

Para atingir o que foi proposto, os consumidores foram submetidos a indicar (1) Motivos que os fazem escolher o Mercado Livre para a compra de um produto, (2) como avaliam os anúncios da plataforma, (3) motivos que o levam a descartar certos anúncios durante a decisão de compra do produto, (4) como avaliam o processo de compra do Mercado Livre.

Após a obtenção dos dados e análise das respostas, foi possível compreender que durante a pandemia do COVID-19, as pessoas foram extremamente influenciadas a realizarem mais compras por meio da internet, concluindo que empreendimentos que apenas possuem lojas físicas, deveriam ter um e-commerce visando alcançar esse público. O uso de e-marketplace seria ideal, tendo em vista que o anunciante não teria gastos com criações de sites, usaria o marketing e a grande quantidade diária de tráfego da plataforma e apenas teria custos quando de fato realizasse a venda do produto, tendo em vista que o Mercado Livre só cobra do vendedor uma taxa após a realização da venda do produto ou serviço.

Pode-se destacar que as principais vantagens percebidas pelos consumidores da plataforma é: a grande quantidade de anúncios do mesmo produto, possibilitando a comparação entre eles; a segurança do site, percebendo que a maioria dos compradores estão cientes de que os produtos adquiridos irão chegar em suas casas; o site possui preços bastante 
competitivos no mercado, sendo um dos principais motivos dos consumidores a escolherem o Mercado livre; a persuasão do frete grátis e a possibilidade de adquirirem produtos que chegarão no dia seguinte após a compra.

Analisando como os respondentes avaliam os anúncios da plataforma, percebe-se que o preço é de extrema importância e tem uma grande relevância na escolha. Produtos com preços altos podem levar o consumidor a desistir da aquisição; a marca dos produtos também influencia bastante a decisão de compra, tendo em vista que as mais conhecidas tendem a ter durações e qualidades maiores; a reputação do vendedor foi a qualidade do anúncio que mais teve votos em extremamente importante, levando a concluir que os consumidores optam por anunciantes que cumprem os prazos de envio, produtos que chegam sem defeitos, realizam a troca quando problemas aparecem no produto e etc. Vendedores com reputação baixa é o principal motivo que levam os respondentes da pesquisa a descartarem o anunciante (como mostra o gráfico 15); os consumidores reconhecem que a quantidade de vendas de um anúncio revela a qualidade do produto; frete grátis, envios no dia seguinte após a compra e empresas vendedoras conhecidas como a Americanas.com dentro do Mercado Livre são um diferencial para a compra, mas não os mais requisitados para a realização do mesmo. Levando em conta o gráfico 15, o elevado preço do frete é o segundo motivo que mais leva o consumidor a desistir daquele anúncio.

O estudo realizado sobre a plataforma tem relevância para os vendedores do site, devido ao foco do estudo ser como os consumidores avaliam os anúncios do Mercado Livre. As análises deste estudo favorecem o entendimento dos pontos positivos e negativos, mostrando o que deve ser melhorado para atrair mais vendas. 


\section{Referências Bibliográficas}

B2 ROCKET. Top 10 marketplaces mais acessados no Brasil [2021]. Disponível em < Top 10 marketplaces mais acessados no Brasil [2021] - B2

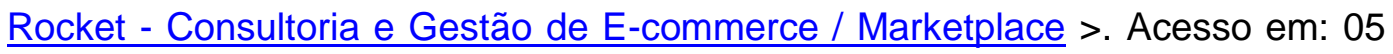
de outubro de 2021.

BERTHOLDO. O que é E-Commerce? Como Funciona e os Melhores em 2021. Disponível em: < https://www.bertholdo.com.br/blog/o-que-e-ecommerce/\#: : :text=E\%2Dcommerce\%20(ou\%20\%E2\%80\%9Ccom\%C3\%A9rcio ,CO > Acesso em: 14 de outubro de 2021.

ECCOMERCE BRASIL. 95\% dos compradores brasileiros utilizam marketplace, revela pesquisa). Disponível em < https://www.ecommercebrasil.com.br/noticias/compradores-brasileirosmarketplace/ >. Acesso em: 03 de outubro de 2021.

ECOMMERCE BRASIL. Como performam e como os consumidores percebem os top marketplaces brasileiros. Disponível em < https://pt.slideshare.net/ecommercebrasil/tendncias-em-marketplace>. Acesso em: 03 de outubro de 2021.

ECOMMERCE BRASIL. O que é Marketplace?. Disponível em < https://www.ecommercebrasil.com.br/artigos/marketplace-vantagens-edesvantagens/ >. Acesso em: 03 de outubro de 2021.

ÉPOCA NEGÓCIOS. 95\% dos brasileiros que compram on-line usam marketpalce, diz estudo. Disponível em < https://epocanegocios.globo.com/Mercado/noticia/2019/11/95-dos-brasileirosque-compram-line-usam-marketplace-dizestudo.htm|\#: : :text=Os\%20marketplaces\%2C\%20sites\%20de\%20com\%C3\%A9 rcio,plataforma\%20nos\%20pr\%C3\%B3ximos\%2012\%20meses >. Acesso em: 03 de outubro de 2021. 
FORBES. Mercado Livre dobra receita no 2o trimestre. Disponível em < Mercado Livre dobra receita no $2^{\circ}$ trimestre - Forbes Brasil >. Acesso em 05 de outubro de 2021.

GIL, A. Carlos. Como Elaborar Projetos de Pesquisa. 4a edição. São Paulo SP: Atlas, 2002.

GOOGLE. Google Forms. Disponível em: < https://www.google.com/intl/ptBR/forms/about/ > Acesso em 21 de outubro de 2021.

KOTLER, Philip; KELLER, Kevin L. Administração de Marketing. 14ª edição. São Paulo: Pearson, 2012.

LINKEDIN. Visão geral Mercado Livre. Rio de Janeiro. Disponível em: < https://www.linkedin.com/company/mercadolivre-com/about/ > Acesso em 07 de dezembro de 2020.

MASCARENHAS, Mariana. O Comércio Eletrônico e o E-Marketplace à Luz do Direito Consumerista Brasileiro. Disponível em < http://repositorio.ufc.br/bitstream/riufc/34027/1/2018 tcc mfmascarenhas.pdf > Acesso em: 12 de outubro de 2021.

MERCADO E CONSUMO. Marketplace é responsável por $78 \%$ do faturamento do e-commerce brasileiro. Disponível em < https://mercadoeconsumo.com.br/2020/08/31/marketplace-e-responsavel-por-78do-faturamento-do-e-commerce-brasileiro/ >.Acesso em: 03 de outubro de 2021.

MERCADO LIVRE. Mercado Livre anuncia resultados do primeiro trimestre de 2021. Disponível em < https://www.mercadolivre.com.br/institucional/noscomunicamos/noticia/resultados-do-primeiro-trimestre-

2021\#deal print id=9ea6bc00-27d4-11ec-a587-6505a6bf997e\&c id=specialwithoutlabel\&c element order $=2 \& c$ campaign $=$ LABEL\&c uid $=9 e a 6 b c 00-27 d 4-$ 11ec-a587-6505a6bf997e >. Acesso em: 07 de outubro de 2021.

MERCADO LIVRE. Mercado Livre: somos a plataforma líder em comércio eletrônico na América Latina. Disponível em < https://www.mercadolivre.com.br/institucional/nos-fazemos/mercado-livre- 
comercio-eletronico\#deal print id=916f71c0-27d5-11ec-8382-

$\underline{55 a d 46 d 89658 \& c \text { id }=\text { special- }}$

withoutlabel\&c element order $=2 \& c$ campaign $=$ LABEL\&c uid $=916 f 71 c 0-27 d 5$ -

11ec-8382-55ad46d89658 > Acesso em: 07 de outubro de 2021.

MERCADO LIVRE. O que é e como funciona a reputação como vendedor.

Disponível em: < https://www.mercadolivre.com.br/ajuda/como-funciona-areputacao-como-vendedor 1382 >. Acesso em: 08 de novembro de 2021.

MERCADO LIVRE. Quanto custa vender um produto. Disponível em: < https://www.mercadolivre.com.br/ajuda/quanto-custa-vender-um-produto 1338 > Acesso em: 13 de outubro de 2021.

MIKAI, Marcus. Comportamento do consumidor e o processo de decisão de compra (com seus 5 estágios simples). Disponível em: < https://www.youtube.com/watch?v=NgCfNJ8uyPs >. Acesso em: 03 de outubro de 2021.

MORO, Alex. Como SABER se o MERCADO LIVRE é CONFIÁVEL ou NÃO? (COMPRA e VENDA). Disponível em: < https://alexmoro.com.br/blog/comosaber-se-o-mercado-livre-e-confiavel-ou-nao-compra-e-venda/ >. Acesso em: 08 de novembro de 2021.

PETER, J. Paul; OLSON, Jerry C. Comportamento do Consumidor e Estratégia de Marketing. São Paulo: Mc Graw Hill, 2009.

RIBEIRO, Vinícius. Comissão Em Marketplace: Quanto Custa Vender Nos Principais Sites Do E-Commerce. Disponível em: < https://magis5.com.br/comissao-em-marketplace-quanto-custa-vender/ > Acesso em: 12 de outubro de 2021.

SALVADOR, Maurício; ALEXANDRE, Miranda. Como Abrir Uma Loja Virtual de Sucesso! 3ae edição. São Paulo - SP: Ed. Do Autor, 2013.

SEBRAE. Canais de Comercialização: Cartilha Marketplace. Disponível em: < https://www.sebrae.com.br/sites/PortalSebrae/ufs/ce/sebraeaz/canais-decomercializacao-cartilha- 
marketplace,f9524d4efe960610VgnVCM1000004c00210aRCRD $>$ Acesso em: 12 de outubro de 2021.

SEBRAE. Conheça as vantagens de marketplace para o seu negócio. Disponível em: $<$ https://www.sebrae.com.br/sites/PortalSebrae/artigos/artigosMercado/conhecaas-vantagens-do-marketplace-para-o-seunegocio,2b1aefa1bbcb1710VgnVCM1000004c00210aRCRD>. Acesso em: 07 de dezembro de 2020.

SEBRAE. Conheça as vantagens de vender seus produtos em um emarketplace. Disponível em: < https://www.sebrae.com.br/sites/PortalSebrae/artigos/conheca-as-vantagens-doe-marketplace-para-os-pequenosnegocios,3f6402b5b0d36410VgnVCM1000003b74010aRCRD > . Acesso em 07 de dezembro de 2020.

SEBRAE. Vamos falar de Marketplace. Disponível em: < https://www.sebrae.com.br/sites/PortalSebrae/sebraeaz/vamos-falar-demarketplace,e01cba088b513710VgnVCM1000004c00210aRCRD >. Acesso em 07 de dezembro de 2020.

SILVA, N. Simões; SENRA, K. Borges; JACOMINO, G. Porfírio; GUARNIERI, Fernanda; BRITTO, L. Ruiz. E-marketplaces: potential channels of online sales performance on-line for e-commerces. Maringá-PR; dez 2018.

SOLOMON, Michael R. O comportamento do consumidor: comprando, possuindo e sendo. 11ª edição. Porto Alegre: Bookman, 2016.

WERTZ, Boris; KINGYENS, Angela Tran. A Guide to Marketplaces. Version One Ventures. Disponível em: < http://versionone.vc/wpcontent/uploads/2015/11/Marketplace-Handbook-11-08-2015.pdf > Acesso em: 12 de outubro de 2021. 


\section{Anexo 1 - Questionário aplicado}

Prezados,

Gostaria muito que respondessem às perguntas abaixo com a maior sinceridade possível.

A pesquisa está relacionada ao meu trabalho de conclusão de curso que tem como objetivo entender o comportamento de compra do consumidor do Mercado Livre.

As respostas são individuais e anônimas. Todas as informações serão mantidas em sigilo e usadas unicamente para fins dessa pesquisa acadêmica.

Desde já, agradeço imensamente pela participação!

Att,

Bernardo Camarotti

Dados demográficos:

1. Qual seu sexo?

( ) Feminino

( ) Masculino

( ) Prefiro não responder

2. Qual sua idade?

( ) até 17 anos

( ) de 18 a 24 anos

( ) de 25 a 31 anos

( ) de 32 a 38 anos

( ) de 39 a 45 anos

( ) de 46 a 52 anos

( ) de 53 a 59 anos 
( ) 60 anos ou mais.

3. Em que região do Brasil você mora?

( ) Norte

( ) Nordeste

( ) Sudeste

( ) Sul

( ) Centro-Oeste

4. Quantas vezes, em média, você compra qualquer produto ou serviço pela Internet?

( ) Nunca comprei.

( ) Compro entre 1 e 2 vezes por mês.

( ) Compro entre 3 e 4 vezes por mês.

( ) Compro entre 5 e 6 vezes por mês.

( ) Compro entre 7 e 8 vezes por mês

( ) Compro mais de 8 vezes por mês.

(se marcar "nunca comprei", pula para o final da pesquisa)

5. A pandemia do COVID-19 te influenciou a realizar mais compras através da internet?

( ) Sim, muito

( ) Sim, razoavelmente

( ) Sim, um pouco

( ) Não influenciou 
6. Você conhece o site (e-marketplace) Mercado Livre?
( ) Sim
( ) Não

(se marcado a opção "não", pula para o final da pesquisa)

7. Com que frequência você realiza compras por meio do Mercado Livre?
( ) Nunca.
( ) Compro entre 1 e 2 vezes por mês.
( ) Compro entre 3 e 4 vezes por mês.
( ) Compro entre 5 e 6 vezes por mês.
( ) Compro entre 7 e 8 vezes por mês
( ) Compro mais de 8 vezes por mês.

8. Como conheceu o e-marketplace Mercado Livre?

( ) Recomendação de terceiros

( ) Anúncio em TV

( ) Anúncio em sites

( ) Anúncio em outdoor

( ) Ferramenta de busca (como Google, Bing etc.) 
9. O que te faz escolher o Mercado Livre para realizar a compra de um produto?

( ) A grande quantidade de anúncios do mesmo produto, podendo comparar preços e benefícios

( ) A Segurança do site

( ) Possibilidade de compra de produtos que chegarão no dia seguinte

( ) Preços baratos

( ) Frete Grátis

( ) Programa de benefícios Mercado Pontos

(O respondente pode sinalizar quantas opções forem necessárias)

10. Como você avaliaria a possibilidade de compra de um produto de determinado vendedor (ou empresa vendedora) dentro do Mercado Livre?

\begin{tabular}{|c|c|c|c|c|c|}
\hline & $\begin{array}{l}\text { Nada } \\
\text { portante }\end{array}$ & $\begin{array}{l}\text { Pouco } \\
\text { portante }\end{array}$ & portante & $\begin{array}{l}\text { Muito } \\
\text { portante }\end{array}$ & $\begin{array}{l}\text { emamente } \\
\text { pportante }\end{array}$ \\
\hline Preço & & & & & \\
\hline Marca & & & & & \\
\hline utação do Vendedor & & & & & \\
\hline $\begin{array}{l}\text { antidade de vendas } \\
\text { e anúncio possui }\end{array}$ & & & & & \\
\hline Frete grátis & & & & & \\
\hline $\begin{array}{l}\text { rega do produto no } \\
\text { a seguinte após a } \\
\text { compra }\end{array}$ & & & & & \\
\hline
\end{tabular}




\begin{tabular}{|c|}
\hline $\begin{array}{l}\text { hpresa vendedora } \\
\text { hecida (ex: Loja da } \\
\text { ricanas.com dentro } \\
\text { o Mercado livre) }\end{array}$ \\
\hline
\end{tabular}

11. O que te faz desistir de uma compra em uma plataforma como o Mercado Livre? (Sinalizar quantas opções forem necessárias)

( ) Preço do frete

( ) Tempo para a entrega do produto

( ) Preço alto

( ) Dificuldade de contato com o vendedor

( ) Reputação do vendedor

( ) Quantidade de vendas do anúncio

( ) Outros:

(O respondente pode sinalizar quantas opções forem necessárias)

12. Das opções citadas na pergunta 11, qual você considera o principal motivo?

( ) Preço do frete

( ) Tempo para a entrega do produto

( ) Preço alto

( ) Dificuldade de contato com o vendedor

( ) Reputação do vendedor

( ) Quantidade de vendas do anúncio

( ) Outros: 
13. Como você avalia o processo de compra no Mercado Livre?

( ) Muito fácil

( ) Fácil

( ) Normal

( ) Difícil

( ) Muito difícil

14. Você recomendaria o Mercado livre para outras pessoas?

( ) Sim

( ) Não (Se marcar "Não", poderia me explicar em "Outros" o porquê?

( ) Outros: 